\title{
Carbon Fixation in Diatoms
}

\author{
Yusuke Matsuda* \\ Department of Bioscience, Research Center for Environmental Bioscience, \\ Kwansei Gakuin University, Sanda, Hyogo 669-1337, Japan \\ and \\ Peter G. Kroth \\ Fachbereich Biologie, Universität Konstanz, D-78457 Konstanz, Germany
}

Summary

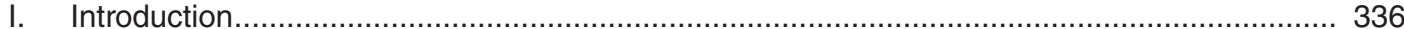

II. Structure of Diatom Cells in Relation to Their Evolutionary History...................................... 337

A. Evolution of Diatoms Based Upon Their Genome Structure .............................. 338

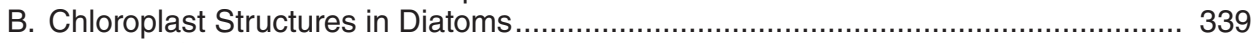

C. Traffic of Small and Large Molecules Across Chloroplast Membranes .................... 340

III. $\mathrm{CO}_{2}$-Concentrating Mechanisms in Cyanobacteria, Green Algae, and Marine Diatoms .......... 341

A. Lessons from Molecular Studies in Cyanobacteria and Green Algae ..................... 341

B. Transports of Inorganic Carbon across the Plasma Membrane and the Chloroplast Envelopes ...................................................................... 342

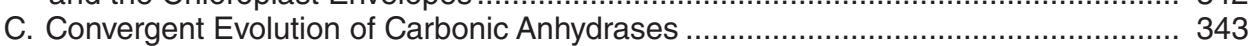

D. Importance of Carbonic Anhydrases in Algal $\mathrm{CO}_{2}$-Concentrating Mechanisms ........ 344

E. Localizations and Functions of Diatom Carbonic Anhydrases............................... 345

$\mathrm{F}$. Is There $\mathrm{a} \mathrm{C}_{4}$ Metabolism in Diatoms? ........................................................ 346

$\mathrm{G}$. Transcriptional Regulation of $\mathrm{CO}_{2}$-Concentrating Mechanism Components ................... 347

IV. Delivery Systems of $\mathrm{CO}_{2}$ to RubisCO and $\mathrm{CO}_{2}$ Fixation................................................. 349

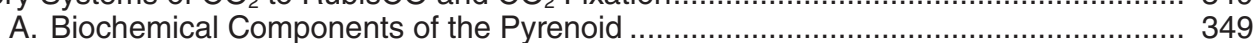

B. Redox Regulation of $\mathrm{CO}_{2}$ Acquisition and Fixation Systems in the Stroma.............. 350

V. Carbon Metabolism Relating to Photosynthesis and Respiration ...................................... 351

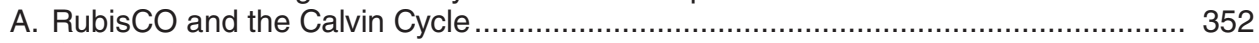

B. Other $\mathrm{CO}_{2}$-Fixing Enzymes in Diatoms

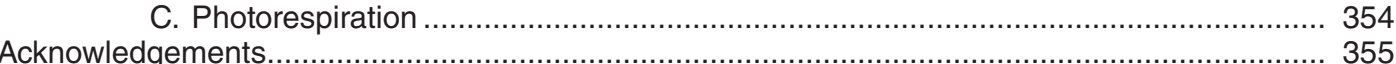

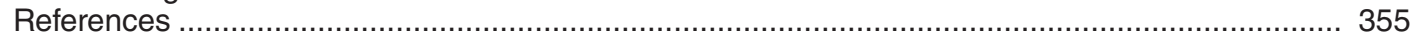

\section{Summary}

Diatoms are unicellular photoautotrophic algae and very successful primary producers in the oceans. Their high primary productivity is probably sustained by their high adaptability and a uniquely arranged metabolism. Diatom belongs to the Chromista, a large eukaryotic group, which has evolved by multiple endosymbiotic steps. As a result, diatoms possess a plastids with four membranes together with complicated translocation systems to transport proteins

*Author for correspondence, e-mail: yusuke@kwansei.ac.jp 
and metabolites including inorganic substances into and out of the plastids. In addition to the occurrence of potential plasma-membrane transporters, there are numerous carbonic anhydrases (CAs) within the matrix of the layered plastidic membranes, strongly suggesting large interconversion activity between $\mathrm{CO}_{2}$ and $\mathrm{HCO}_{3}^{-}$within the chloroplast envelope as a part of a $\mathrm{CO}_{2}$-concentrating mechanism $(\mathrm{CCM})$. In diatoms also the Calvin cycle and its adjacent metabolism reveal unique characteristics as, for instance, ribulose-1,5-bisphosphate carboxylase/oxygenase (RubisCO) activase, the plastidic sedoheptulose-1,7-bisphosphatase (SBPase), and the plastidic oxidative pentose phosphate pathway (OPP) are absent. Furthermore, the Calvin cycle metabolism in diatoms is not under the strict redox control by the thioredoxin (Trx) system. Instead, a $\mathrm{CO}_{2}$-supplying system in the pyrenoid shows $\mathrm{CA}$ activities which are probably regulated by chloroplastic Trxs. Pyrenoidal CAs are also regulated on the transcriptional level by $\mathrm{CO}_{2}$ concentrations via cAMP as a second messenger, suggesting an intense control system of $\mathrm{CO}_{2}$ acquisition in response to $\mathrm{CO}_{2}$ availability. The photorespiratory carbon oxidation cycle (PCOC) is the major pathway to recycle phosphoglycolate in diatoms although this process might not be involved in recycling of 3-phosphoglycerate but instead produces glycine and serine. In this review we focus on recent experimental data together with supportive genome information of $\mathrm{CO}_{2}$ acquisition and fixation systems primarily in two marine diatoms, Phaeodactylum tricornutum and Thalassiosira pseudonana.

\section{Introduction}

Diatoms have a rather complicated evolutionary history including multiple endosymbiotic events, which have involved unknown host cells as well as cyanobacteria, a red alga and possibly a green alga (Moustafa et al. 2009). As a result of the cellular reorganization following secondary endosymbiosis, diatoms possess four layers of chloroplast envelope membranes, with the outermost being linked to the ER-nuclear envelope network, and a highly redundant metabolic system cooperating across organelles (Kroth

\footnotetext{
Abbreviations: AC - Adenylyl cyclase; CA - Carbonic anhydrase; $\mathrm{CCM}-\mathrm{CO}_{2}$-concentrating mechanism; DIC-Dissolved-inorganic carbon; FBA-Fructose-1,6bisphosphate aldolase; FBPase - Fructose-1,6bisphosphatase; Fd - Ferredoxin; HGT - Horizontal gene transfer; LCI - Low- $\mathrm{CO}_{2}$-inducible proteins; NTT - Nucleotide translocators; OPP - Oxidative pentose phosphate pathway; PCOC - Photorespiratory carbon oxidation cycle; PEPCK - Phosphoenol pyruvate carboxykinase; PPDK - Pyruvate orthophosphate dikinase; RubisCO-Ribulose-1,5-bisphosphatecarboxylase/ oxygenase; SLC - Solute carrier; Trx - Thioredoxin
}

et al. 2008; Prihoda et al. 2012). Marine diatoms are major primary producers responsible for up to one fifth of global carbon fixation (Tréguer et al. 1995; Falkowski et al. 2000) and their mechanisms for $\mathrm{CO}_{2}$ fixation have important implications for biogeochemistry. Like cyanobacteria and green algae, diatoms are believed to possess $\mathrm{CO}_{2}-$ concentrating mechanisms (CCMs), which accumulate dissolved inorganic carbon (DIC) by pumping DIC biophysically from the surrounding media. This stored carbon is then mobilized by internal carbonic anhydrases (CAs), which are located in multiple intracellular compartments (Tachibana et al. 2011). The operation of CCMs is probably crucial in the ocean environment because of its high alkalinity and salinity, which change the equilibrium of DIC species and result in reduced rates of $\mathrm{CO}_{2}$ formation via $\mathrm{HCO}_{3}^{-}$ breakdown and dehydration of $\mathrm{H}_{2} \mathrm{CO}_{3}$ (Goyet and Poisson 1989; Matsuda et al. 2001). This physical environment negatively effects the low affinity system of the major $\mathrm{CO}_{2}$-fixing enzyme, ribulose-1,5-bisphosphate carboxylase/oxygenase (RubisCO) in diatoms. A part of the CCM in diatoms is thought to be 
linked to $\mathrm{C}_{4}$ type organic acid accumulation in some diatom strains (Reinfelder et al. 2004). This biochemical CCM would be enabled by a redundant organization of (de-) carboxylase enzymes presumably inherited from multiple symbiosis partners and by horizontal gene transfer (HGT) from bacteria. However, molecular details of these biophysical and biochemical CCMs are so far almost totally unknown in diatoms.

The recent annotation of diatom genomes revealed that a number of metabolic pathways involved in carbon metabolism and photosynthesis might be duplicated and/or shifted to different intracellular locations (Bowler et al. 2008; Kroth et al. 2008; Allen et al. 2012). Diatoms possess a large number of isoenzymes that according to phylogenetic analyses originate from different sources including the cyanobacterial primary endosymbiont, the primary and secondary host cells and from HGT from bacteria (Kilian and Kroth 2004; Moustafa et al. 2008; Allen et al. 2011). Consequently, diatoms seem to have developed an unusual metabolic cooperation across organelles and redundant duplications of pathways (Kroth et al. 2008; Prihoda et al. 2012). Cooperation on the metabolic level requires the exchange of substrates between the organelles. This strongly suggests the presence of a number of specific channels and transporters in the membrane systems of mitochondria, chloroplasts, and peroxysomes. In diatoms this exchange is especially complicated considering the additional chloroplast envelope membranes (see below).

There are thousands of unique genes in the diatom genomes, whose functions are yet completely unclear, and which may be involved in unknown processes of diatom carbon metabolism. Genetic tools to study molecular aspects of diatom physiology/ biochemistry are so far limited, and there is no established system to control ploidy and the sexual reproduction cycle. Hence predictions of the functions of diatom genes so far largely rely on bio-informatics (Kroth et al. 2008; Fabris et al. 2012). However, recent technological improvements in genetic transformation (Zaslavskaia et al. 2000; Poulsen et al. 2006) and gene silencing (De Riso et al. 2009; Sakaguchi et al. 2011; Lavaud et al. 2012) of diatoms open the gate for functional identifications of genes by reverse genetics. In this chapter, we discuss molecular aspects of the carbon acquisition system, mechanisms of carbon fixation, and the respective carbon metabolism in diatoms, which includes information predicted from the genome analyses, focusing on data with direct experimental support. Although carbon metabolism is strongly connected to photosynthetic electron transport, we have excluded this topic, as it goes far beyond the scope of this review.

\section{Structure of Diatom Cells in Relation to Their Evolutionary History}

Diatom cells possess a silica-based cell wall. The main parts of the cell wall (termed valve) have highly symmetrical shapes and nanopores (termed areolae) within, whose structures must be imprinted in the genome as they are highly specific for individual species. Due to such chemically stable and geometrically shaped cell walls, diatoms have readily become well identifiable fossils and thus their emergence in the history of the earth is relatively clear. The oldest diatom fossils from the Jurassic are about 180 million years old (Kooistra et al. 2007), thus it is thought that diatoms have evolved in the Metazoic, most probably as marine species with radially symmetrical valves. This oldest type of diatoms are called Centrales or centric diatoms (Sims et al. 2006). Pennate diatoms (Pennales, bilaterally symmetrical) separated from the centrics in the late Cretaceous (Sims et al. 2006). After the Oligocene, diatom populations have expanded and diversified vigorously to about a 100,000 species, which also is their estimated number today (Norton et al. 1996; Prihoda et al. 2012). 


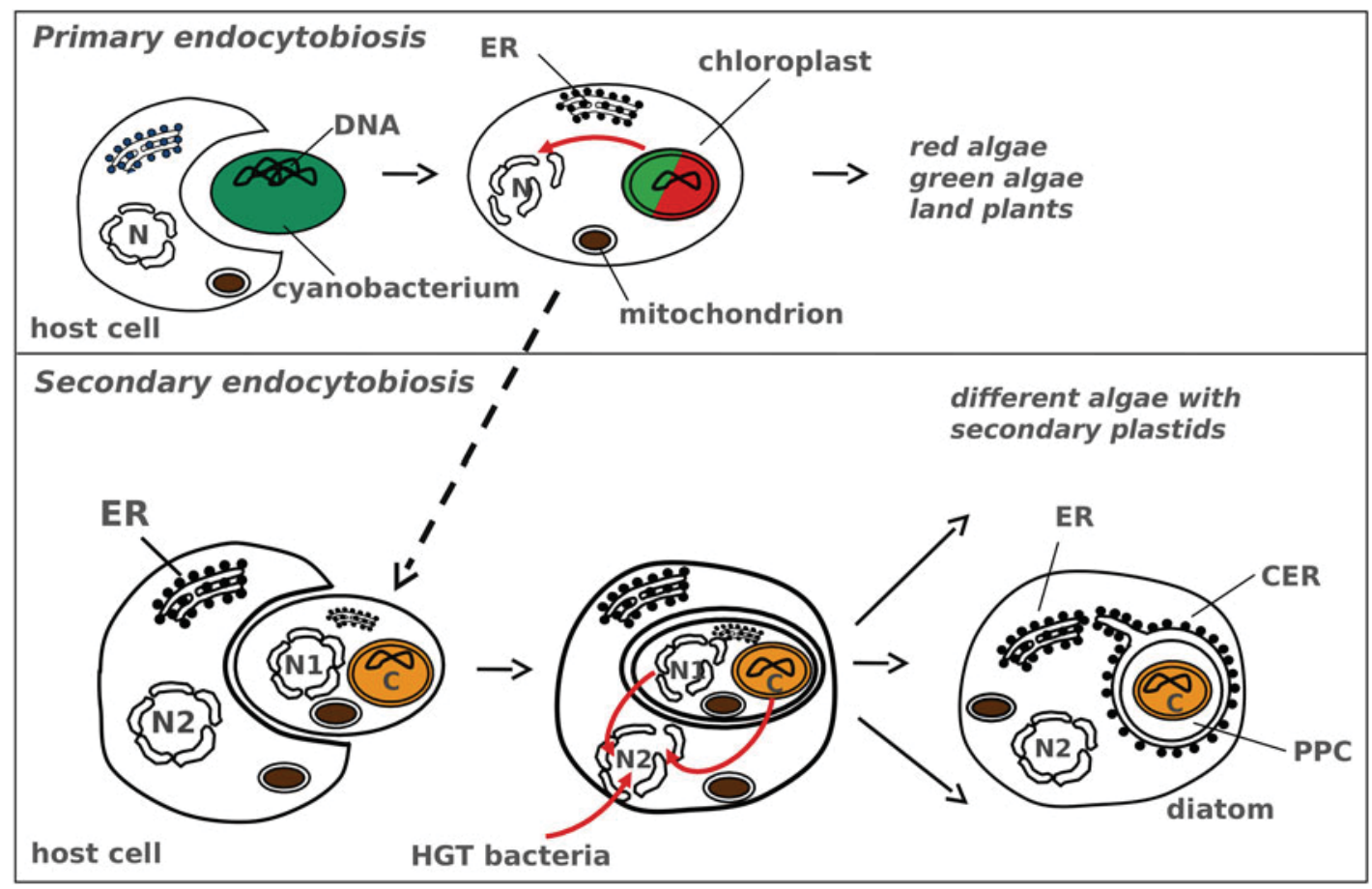

Fig. 18.1. Cellular processes involved in primary and secondary endosymbiotic events. Top: In the primary endocytobiosis event a unicellular cyanobacterium apparently has been taken up by a eukaryotic cell into a food vacuole. After the endosymbiont persisted in this vacuole, most of the genes of the endosymbiont had been transferred to the nucleus of the host cell. The eukaryotic algal ancestor developed into the different lineages of rhodophytes, glaucophytes and chlorophytes. Bottom: In a secondary endocytobiotic step, eukaryotic ancestors of either green or red algae were taken up by eukaryotic cells. Here only one possible development is shown including the reduction of redundant components of the endosymbiont-like nucleus, mitochondria, ER and further components. In diatoms, a later fusion of the food vacuole with the ER system of the secondary host cell allowed the utilization of the CER for cotranslational import of proteins into the plastids that possess four surrounding membranes. $E R$ endoplasmic reticulum, $C E R$ chloroplast endoplasmic reticulum $N$ nucleus, $H G T$ horizontal gene transfer, $P P C$ periplastidic compartment; red arrows: gene transfer processes.

\section{A. Evolution of Diatoms Based Upon Their Genome Structure}

As described above, diatoms are among the youngest groups of eukaryotic photoautotrophs. They belong to a large eukaryotic supergroup informally called the chromalveolates, comprising the chromista and the alveolates (Cavalier-Smith 1999). Within this group, there are a number of important marine primary producers, like the chromist algae (brown algae, diatoms, haptophytes and cryptomonads) and some plastid-bearing alveolates (dinoflagellates) (Cavalier-Smith 2000). Chromalveolates (and other groups such as excavates and rhizaria) arose by secondary endosymbioses. From the comparative analyses of multiple genes encoded on the genome of the chlorophyll $c$-containing plastids, it is thought that a diverse group of secondary endosymbionts arose either by a single or up to five independent events of phagocytosis of a red alga probably by a biciliate protozoan about 1,200 million years ago (Delwiche and Palmer 1997; CavalierSmith 1999; Yoon et al. 2002). The food vacuole, created in the host cell upon phagocytosis of the red alga, in turn became a stable peripheral vacuole. In the case of the evolution of chromista, this peripheral vacuole has fused with the nuclear envelope, placing the acquired chloroplast in the rough ER lumen (Cavalier-Smith 2000) (Fig. 18.1). This way chromist algae, including diatoms, have 
Table 18.1. Size of diatom genomes.

\begin{tabular}{lcll}
\hline Species name & Genome size & Number of ORF & Reference \\
\hline Thalassiosira pseudonana & $32 \mathrm{Mb}$ & $\sim 11,000$ & Armbrust et al. (2004) \\
Phaeodactylum tricornutum & $27 \mathrm{Mb}$ & $\sim 10,000$ & Bowler et al. (2008) \\
Fragilariopsis cylindrus & $80 \mathrm{Mb}$ & $\sim 27,000$ & JGI $^{\mathrm{a}}$ \\
Pseudo-nitzschia multiseries CLN-47 & $218 \mathrm{Mb}$ & $?$ & JGI $^{\mathrm{b}}$ \\
\hline
\end{tabular}

${ }^{a}$ http://genome.jgi-psf.org/Fracy1/Fracy1.home.html

${ }^{\mathrm{b}} \mathrm{http} / / / \mathrm{genome.jgi-psf.org/Psemu1/Psemu1.home.html}$

established a very stable nucleus-chloroplast association (Fig. 18.1), which, howver, may be physically constraining the behavior of these two housekeeping organelles.

The first diatom nuclear genome that was fully sequenced belongs to the multipolar centric Thalassiosira pseudonana (Armbrust et al. 2004), followed by the nuclear genome of the raphid pennate diatom Phaeodactylum tricornutum (Bowler et al. 2008). Plastid and mitochondrial genomes of these model diatoms were also sequenced and compared to other genomes (Oudot-Le Secq et al. 2007; Oudot-Le Secq and Green 2011). The size of the nuclear genomes and the number of genes encoded are summarized in Table 18.1. Recent analyses of the genomes have revealed numerous footprints of an enrichment of foreign nuclear genes via serial endosymbioses, and HGT from proteobacteria as well as from Chlamydiae (Bowler et al. 2008; Moustafa et al. 2009). Of particular interest is that, in spite of possessing plastids of red algal origin, the diatoms P. tricornutum and T. pseudonana have a large number of nuclear genes that apparently are more related to green algae than to red algae (Moustafa et al. 2009). About 2,500 green or red type genes were identified in the nuclear genomes of these diatoms with about $70 \%$ apparently being green-type genes, which accounts for $16 \%$ of the nuclear genome, while only $5 \%$ of the nuclear genome could be categorized to red-type genes (Moustafa et al. 2009; Prihoda et al. 2012). It is thus suggested that an ancestor of modern green algae might have been the first eukaryotic symbiosis partner, which later was replaced by an ancestor of red alga (Moustafa et al. 2009; Prihoda et al. 2012), however, there is still a controversy about the statistical sig- nificance of the genomic data (Deschamps and Moreira 2012). Apparently most genes for the photosynthetic apparatus were transferred from the initial green plastid to the nucleus of the host cell and kept even after the secondary red plastid was established, (Moustafa et al. 2009). These serial secondary endosymbioses together with the subsequent HGT events from bacteria have genetically enriched the nuclear genome of diatoms (Bowler et al. 2008; Moustafa et al. 2009; Qiu et al. 2013) (Fig. 18.1).

\section{B. Chloroplast Structures in Diatoms}

As described above, diatom chloroplasts are in a firm physical association with the nucleus linked by an ER network (Fig. 18.1). The outermost membrane of the chloroplast is termed chloroplast ER membrane (CER). In electron micrographs this membrane is often studded with ribosomes similarly as the rough ER (Fig. 18.1). The space between the CER membrane and the next envelope membrane is called CER lumen and probably is continuous with the ER lumen. The space between the second and the third membrane is called periplastidal compartment (PPC) and probably represents the strongly reduced cytosol of the secondary endosymbiont. The two inner membranes apparently are homologous to the two envelope membranes of red algal plastids (Fig. 18.1). The thylakoids in diatoms are generally stacked in pairs of three without grana, while directly below the innermost membrane there is a stack of three thylakoids surrounding most of the plastid (girdle lamella) (Fig. 18.1). In the central part of the chloroplast, there is a large undefined proteinaceous body called pyrenoid, which usually is penetrated 


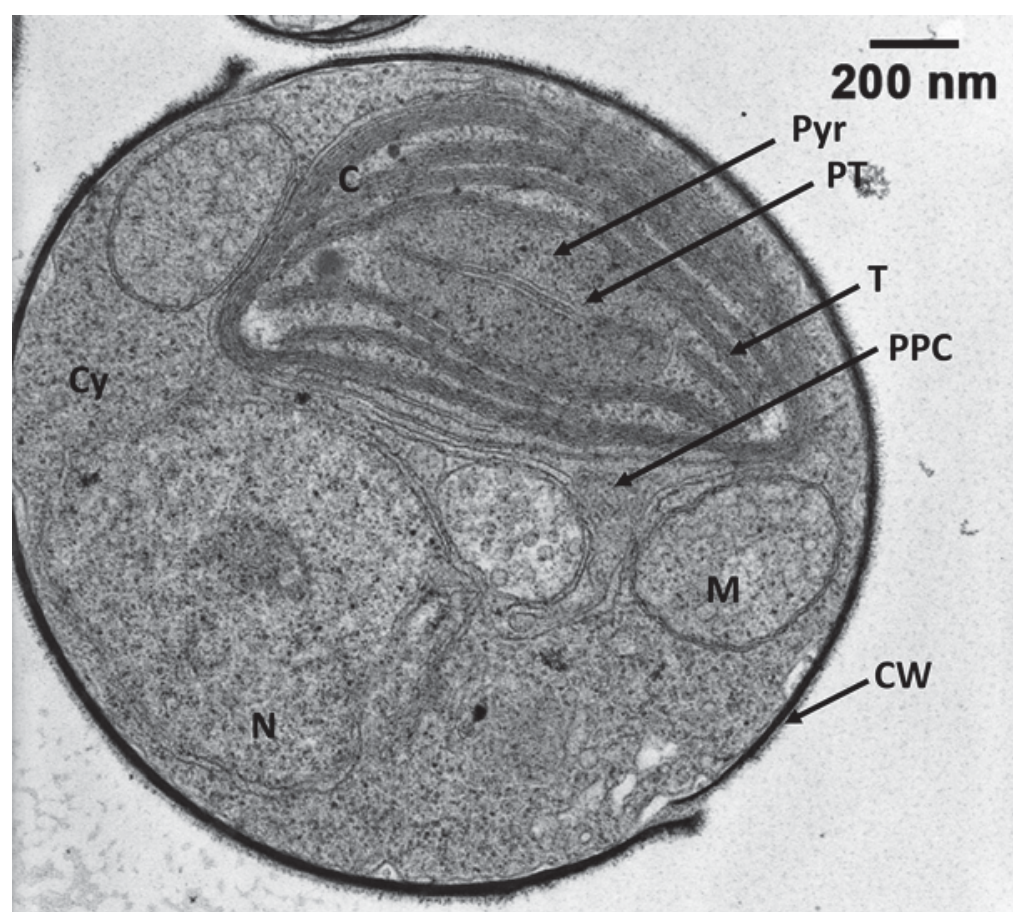

Fig. 18.2. Electron micrograph of a cross-section of P. tricornutum showing the plastid (C) including the pyrenoid (Pyr), the internal thylakoid membranes (PT), the regular thylakoid membranes (T) and the periplastidal compartment (PPC). $M$ mitochondria, $N$ Nucleus, $C y$ cytosol, $C W$ cell wall (The images are shown by courtesy of A. Gruber and J. Hentschel, Universität Konstanz).

by a single line of thylakoid membranes (Fig. 18.2). Recent improvements of molecular-labeling techniques using fluorescent proteins like GFP have revealed reticular or vesicular structures that might be located in the CER (Kilian and Kroth 2005). This structure denoted as blob-like structure (BLS) is often observed when periplastidal preproteins or stromal preproteins with modified presequences fused to GFP are expressed in P. tricornutum. Thus this structure probably represents an accumulation of proteins in a certain area of the periplastidic space; however, structural details of BLS are unknown yet.

\section{Traffic of Small and Large Molecules Across Chloroplast Membranes}

Biomembranes represent unique barriers for the translocation of smaller molecules like metabolites or larger molecules like polypep- tide chains. Membrane transporters are a large, structurally and functionally heterogeneous group of proteins, consisting of carriers and channels that span lipid bilayers. Chan et al. (2011, 2012) have compiled a large number of putative translocators by studying diatom genomes. However, the functionality of these proteins still has to be confirmed experimentally. Studying nucleotide import translocators, Ast et al. (2009) discovered the presence of six different nucleotide translocators (NTT) in P. tricornutum (and eight in T. pseudonana), which fall into three classes: some do not possess a presequence, others possess a signal and a transit peptide domain, while the third group additionally shows an "ASAFAP" motif (Gruber et al. 2007), leading to the suggestion that these translocators are integrated in different plastid envelope membranes. Two translocators have been studied more thoroughly, NTT1 and NTT2. NTT1 is more similar to 
plastid translocators of land plant and algal plastid ATP/ADP exchangers while NTT2 is related to nucleotide importers from parasitic endocytic bacteria. Interestingly the diatom NTT1 shows properties of an $\mathrm{H}^{+}$-driven ATP translocator, and NTT2 of a nucleotide exchanger (Ast et al. 2009), indicating that the original functional properties of these translocators have been completely altered in diatoms. The apparent capability of diatoms to acquire and combine different translocator systems in order to overcome the additional barriers represented by the four plastid envelope membranes is also reflected in the plastid protein import machinery. Targeting of proteins into diatom plastids has been studied intensely in the recent years. Analyses of nuclear-encoded plastid proteins revealed the presence of an N-terminal ER targeting signal peptide fused to a transit peptide domain known from land plant plastids (Kroth 2002). The presequence structure of proteins targeted to the stroma additionally possesses an "ASAFAP" motif at the interface of both domains. Interestingly the penylalanine residue in this motif appears to be essential for a complete import (Kilian and Kroth 2005). Although the details of import pathway have not been solved yet completely, there is evidence that four different import machineries are involved in this process: (i) in a first step the protein is targeted cotranslationally across the CER membrane using the ER Sec system (Lang et al. 1998), (ii) in the next step a duplicated endosymbiont-specific ER-associated degradation system for lumenal proteins (ERAD-L) may be involved (Sommer et al. 2007), (iii) the next membrane may be traversed by a translocator similar to bacterial Omp85 and plastidic Toc75 proteins (Bullmann et al. 2010), while (iv) for the innermost membrane a protein complex related to plastidic Tic complexes may be involved (Vugrinec, Gruber, Kroth, unpublished). Once the proteins have entered the stroma, they can be sorted to further compartments like the innermost of the four membranes surrounding the plastids, the thylakoid membrane or the thylakoid lumen. Similar to land plant plastids, different import pathways are known for targeting proteins into diatom thylakoids (Lang and Kroth 2001; Chaal et al. 2003).

\section{III. $\mathrm{CO}_{2}$-Concentrating Mechanisms in Cyanobacteria, Green Algae, and Marine Diatoms}

The entry of $\mathrm{CO}_{2}$ into plant cells is a limiting factor of $\mathrm{CO}_{2}$ acquisition for a large majority of autotrophic organisms from chemolithotrophic bacteria to higher plants. In higher plants, $\mathrm{CO}_{2}$ permeates across mesophyll cells through specific channels that belong to the family of aquaporins (Uehlein et al. 2003). The acquisition of $\mathrm{CO}_{2}$ in water is further hampered, as the concentration of $\mathrm{CO}_{2}$ dissolved in water is very low (less than $15 \mu \mathrm{M}$ at the current atmospheric $p \mathrm{CO}_{2}$ at $20{ }^{\circ} \mathrm{C}$ ) and diffusion constants of dissolved molecules are $10^{4}$ times smaller compared to those of the gaseous state (Badger et al. 1998). This problem is more serious in marine environments because of the highly alkaline/saline seawater, in which $\mathrm{CO}_{2}$ formation from $\mathrm{HCO}_{3}^{-}$is significantly slower $(1 / 4 \sim 1 / 8)$ compared to that in freshwater (Matsuda et al. 2001). Aquatic photoautotrophs thus experience difficulties in acquiring $\mathrm{CO}_{2}$ from surrounding media and it has been demonstrated that they generally are able to take up both $\mathrm{CO}_{2}$ and $\mathrm{HCO}_{3}{ }^{-}$to accumulate dissolved-inorganic carbon (DIC) intracellularly, a process which also is termed biophysical $\mathrm{CO}_{2}$-concentrating mechanism (CCM) (Badger et al. 1998; Falkowski and Raven 2007; Hopkinson et al. 2011).

\section{A. Lessons from Molecular Studies in Cyanobacteria and Green Algae}

Molecular details of the CCMs have been studied in cyanobacteria, where a whole set of CCM components, has been elucidated that fully account for the cyanobacterial $\mathrm{CCM}$. In freshwater $\beta$-cyanobacteria, $\mathrm{HCO}_{3}{ }^{-}$ is directly taken up by three plasma-membrane $\mathrm{HCO}_{3}^{-}$transporters, a bicarbonate transporter 1 (BCT1), a sodium bicarbonate 
transporter A (SbtA), and a bicarbonate transporter A (BicA). Permeated $\mathrm{CO}_{2}$ is also converted into $\mathrm{HCO}_{3}^{-}$by the NADPHdehydrogenase- $\mathrm{CO}_{2}$-hydration protein $(\mathrm{Ndh}-$ Chp) complexes at the thylakoid membrane and perhaps at the cytoplasmic membrane (Omata et al. 1999; Maeda et al. 2002; Shibata et al. 2002; Price et al. 2004). Accumulated $\mathrm{HCO}_{3}^{-}$, a leakage resistant form of dissolved-inorganic carbon (DIC), is then converted into $\mathrm{CO}_{2}$ only when $\mathrm{HCO}_{3}{ }^{-}$ passes across the shell of the carboxysome, an icosahedronic crystal body in the cell (Kerfeld et al. 2005) (see Chap. 7). This process is catalyzed by a carbonic anhydrase (CA), a component of the carboxysome shell (So et al. 2002), and released $\mathrm{CO}_{2}$ is fixed by RubisCO within the carboxysome. The carboxysomes of similar structural characteristics are also detected in chemolithotrophs like Halothiobacillus neapolitanus (Dou et al. 2008). Cyanobacterial cells (see Chap. 14) at full operation of the CCM behave like a leakage-proof $\mathrm{HCO}_{3}^{-}$chamber with an "efficient $\mathrm{CO}_{2}$-formation and fixation reactor", which is the carboxysome.

The cyanobacterial system is believed to have evolved after the primary endosymbiosis (Badger et al. 2002). Algal cells have developed a different-type of CCM based upon the pyrenoid. The presence of a pyrenoid does not necessarily mean that the cells possess a CCM (Morita et al. 1998; Ratti et al. 2007; Genkov et al. 2010), but there is the possibility that the pyrenoid functions as a focal point of the CCM. There is some evidence for biochemical functions of the pyrenoid in microalgae. In the freshwater chlorophyte Chlamydomonas reinhardtii, a thylakoid-lumenal CA (CAH3), and a pyrenoidal component denoted Low$\mathrm{CO}_{2}$-inducible proteins LCIB and LCIC have been demonstrated to provide $\mathrm{CO}_{2}$ supply to RubisCO under moderately limiting $\mathrm{CO}_{2}$ conditions (Spalding et al. 1983; Yamano et al. 2010). CAH3 presumably forms $\mathrm{CO}_{2}$ from $\mathrm{HCO}_{3}{ }^{-}$utilizing the acidity of the thylakoid lumen, while the LCIB/C complex is speculated to recapture the $\mathrm{CO}_{2}$ leaking out of the stroma, forcing it back to the pyrenoid (Yamano et al. 2010; Duanmu and Spalding 2011). A plasma-membrane transporter, LCI1, has been demonstrated to be a $\mathrm{HCO}_{3}^{-}$channel which also facilitates the $\mathrm{CO}_{2}$ acquisition of $C$. reinhardtii under $\mathrm{CO}_{2}$ limitation (Ohnishi et al. 2010). The function of extracellular CAs as a part of the green algal CCM has been discussed controversially (see Ynalvez et al. 2008).

\section{B. Transports of Inorganic Carbon across the Plasma Membrane and the Chloroplast Envelopes}

Both, freshwater and marine diatoms, have been shown to actively take up $\mathrm{HCO}_{3}{ }^{-}$and/or $\mathrm{CO}_{2}$ (Patel and Merrett 1986; Colman and Rotatore 1995; Rotatore et al. 1995; Johnston and Raven 1996; Mitchell and Beardall 1996; Korb et al. 1997; Burkhardt et al. 2001; Rost et al. 2003; Trimborn et al. 2008). The list in Table 18.2 (redrawn from Matsuda et al. 2011) shows the respective results in a number of publications, which all employed relatively direct and reliable measures of DIC accumulations: (silicon-oil centrifugation: SOC) or steady-state DIC flux (membrane-inlet mass spectrometry: MIMS; isotopic disequilibrium technique: IDT). Accordingly, it is clear that these diatom species can take up both $\mathrm{CO}_{2}$ and $\mathrm{HCO}_{3}{ }^{-}$ from the surrounding media with significant species-dependent preferences of the respective DIC molecules. Probably, $\mathrm{HCO}_{3}{ }^{-}$consumers have adapted to use abundant $\mathrm{HCO}_{3}^{-}$ in seawater, albeit direct uptake of $\mathrm{HCO}_{3}^{-}$ can be energetically expensive. Conversely, in marine photoautotrophs, $\mathrm{HCO}_{3}^{-}$uptake has been reported to be mediated by an external CA form, which might be a less energy consuming strategy for the use of external $\mathrm{HCO}_{3}^{-}$. However, so far there is little molecular evidence, and proteins involved in DIC uptake and the mechanisms of DIC flux regulations within the diatom cells are not known.

A recent study has revealed that plasma membrane-type transporters homologous to the mammalian solute-carrier (SLC) family work as an initial entry gate of DIC in marine diatoms in a low $\mathrm{CO}_{2}$ environment 
Table 18.2. Dissolved inorganic carbon species taken up by diatoms (Redrawn from Matsuda et al. 2011).

\begin{tabular}{|c|c|c|c|c|c|}
\hline \multirow[b]{2}{*}{$\underline{\text { Species }}$} & \multirow[b]{2}{*}{$\mathrm{pH}$ at measurement } & \multicolumn{2}{|c|}{ DIC Transport } & \multirow[b]{2}{*}{ Method } & \multirow[b]{2}{*}{ Reference } \\
\hline & & $\mathrm{CO}_{2}$ & $\mathrm{HCO}_{3}^{-}$ & & \\
\hline Stellarima stellaris & $7.9-8.4$ & No & Yes & MIMS & Trimborn et al. (2008) \\
\hline Pseudo-nitzschia multiseries & $7.9-8.4$ & Yes & Yes & MIMS & Trimborn et al. (2008) \\
\hline Nitzschia navis-varingica & $7.9-8.4$ & Yes & No & MIMS & Trimborn et al. (2008) \\
\hline Nitzschia frigida & 7.5 & Yes $^{\mathrm{a}}$ & & $\mathrm{SOC}$ & Mitchell and Beardall (1996) \\
\hline \multirow[t]{5}{*}{ Phaeodactylum tricornutum } & 8.0 & Yes & & SOC & Patel and Merrett (1986) \\
\hline & 7.5 & Yes & & SOC & Colman and Rotatore (1995) \\
\hline & 8.0 & Yes & Yes & MIMS & Burkhardt et al. (2001) \\
\hline & 7.5 & Yes & & SOC & Colman and Rotatore (1995) \\
\hline & 8.0 & Yes & & SOC & Johnston and Raven (1996) \\
\hline \multirow[t]{2}{*}{ Cyclotella sp. } & 7.5 & Yes & & SOC & Colman and Rotatore (1995) \\
\hline & 7.5 & Yes & - & MIMS & Rotatore et al. (1995) \\
\hline Thalassiosira weissflogii & 8.0 & Yes & Yes & MIMS & Burkhardt et al. (2001) \\
\hline \multirow[t]{2}{*}{ Skeletonema costatum } & 8.0 & Yes & Yes & IDT & Korb et al. (1997) \\
\hline & 8.0 & Yes & Yes & MIMS & Rost et al. (2003) \\
\hline Ditylum brightwellii & 8.0 & Yes & Yes & IDT & Korb et al. (1997) \\
\hline Chaetoceros calcitrans & 8.0 & Yes & Yes & IDT & Korb et al. (1997) \\
\hline
\end{tabular}

MIMS membrane inlet mass spectrometry, SOC silicon-oil centrifugation, ITD isotopic disequilibrium technique ${ }^{a} \mathrm{Ci}$ species could not be differentiated

(Nakajima et al. 2013). One subfamily of the diatom SLC, PtSLC4-2, was shown to transport specifically $\mathrm{HCO}_{3}^{-}$in the presence of relatively high concentrations of sodium ions with a saturation point of about $100 \mathrm{mM} \mathrm{Na}^{+}$ (Nakajima et al. 2013; Hopkinson 2013). This protein, together with other two closely related putative transporters PtSLC4-1 and PtSLC4-4 are induced specifically under $\mathrm{CO}_{2}$-limited conditions, indicating that several transporters engage in the enhancement of $\mathrm{HCO}_{3}^{-}$influx into the cell and perhaps into the plastid under low $\mathrm{CO}_{2}$ conditions (Nakajima et al. 2013; Hopkinson 2013). Accumulated DIC might pass across the chloroplast membranes by specific transporters (Hopkinson 2013) and CAs densely localized in the matrixes of the four-layered chloroplast membranes very likely control the efficiency of permeation (Tachibana et al. 2011; Samukawa et al. 2014). It is interesting that diatom's SLC4 family transporters cluster phylogenetically with members of the human SLC4 family with reasonably high bootstrap values at the transmembrane region (Nakajima et al. 2013), while $\mathrm{HCO}_{3}{ }^{-}$ transporters already identified in cyanobacteria and $C$. reinhardtii do not share homology with the respective proteins in diatoms. This strongly suggests that eukaryotic algae perhaps have acquired $\mathrm{HCO}_{3}{ }^{-}$transporters independently from various ancestral eukaryotic hosts. Indeed, it has been suggested that diatom transporters share a common origin with those in human cells (Nakajima et al. 2013).

\section{Convergent Evolution of Carbonic Anhydrases}

There are six subtypes of CAs so far found in living organisms and they are categorized from $\alpha$ to $\zeta$ (Tripp et al. 2001; So et al. 2004; Lane et al. 2005). The $\alpha$-CAs are found predominantly in animals but also occur in bacteria, higher plants and green algae, the $\beta$-CAs are known to be abundant in plants, green algae, eubacteria and archaea, and the $\gamma$-CAs may be the most ancient form protein related to CAs. They have evolved long before the $\alpha$ class and are predominantly found in bacteria, although their activity is so far confirmed only in very limited candidates (Tripp et al. 2001). The eukaryotic algae studied so far possess $\alpha$ - to $\gamma$ - CAs 
(Satoh et al. 2001), with some exceptions such as the red alga Cyanidioschyzon merolae, which lacks $\alpha$-CA genes (Matsuzaki et al. 2004). Interestingly, among diatoms, $\beta$-type CAs have only been found so far in the pennate diatom P. tricornutum, but there is no homologous gene in the genome of the centric diatom $T$. pseudonana (Montsant et al. 2005; Tachibana et al. 2011) or the polar-sea species, Fragilariopsis cylindrus, (http://genome.jgi-psf.org/Fracy1/Fracy1. home.html).

The $\delta$ - and $\zeta$-type CAs are unique in diatoms and were first discovered in Thalasiossira weissflogii, denoted as TWCA1 and CDCA1 (Roberts et al. 1997; Lane and Morel 2000; Lane et al. 2005; Xu et al. 2008). These two CA types are also present in the centric diatom T. pseudonana, while a $\delta$-type CA was found in the haptophyte Emiliania huxleyi (Soto et al. 2006) and the dinoflagellate Lingulodinium polyedrum (Lapointe et al. 2008). These two "marine CAs" were identified as bona fide CAs (Xu et al. 2008; Viparelli et al. 2010; Alterio et al. 2012; Lee et al. 2013). The crystal structure of the $\zeta$-type CA has revealed a striking similarity of the active center structure to that of $\beta$-CA (Xu et al. 2008), while the active center of $\delta$-CA is reported to be similar to that of $\alpha$-CA (Cox et al. 2000). Indeed, it was recently reported that $\delta$-CA in $T$. weissflogii possess an esterase activity, a feature unique to $\alpha$-CAs (Lee et al. 2013).

The $\varepsilon$-CA was first identified in the chemolithotrophic bacterium $H$. neapolitanus as CsoS3/CsoSCA, representing a component of the carboxysomal shell. Genes homologous to $\operatorname{csoS} 3$ were also found in cyanobacteria and chemolithotrophic bacteria (So et al. 2004). Since the crystal structure of $\varepsilon$-CA is very similar to $\beta$-type CAs, despite its unique primary amino acid sequence, this protein was later recategorized into $\beta$-type CA (Sawaya et al. 2006). CsoS3/CsoSCA is essential for the operation of the CCM in $H$. neapolitanus because of its role in dehydrating $\mathrm{HCO}_{3}{ }^{-}$at the carboxysomal shell in order to supply $\mathrm{CO}_{2}$ to RubisCO within the carboxysome (Dou et al. 2008).
The discovery of these novel lineages of convergent evolution revealed a strong variation between CAs that have evolved from an unexpectedly wide variety of origins and functions in marine autotrophs. Moreover, the cofactor of diatom's $\zeta$-CAs can be substituted by $\mathrm{Cd}$ when $\mathrm{Zn}$ is not available (Xu et al. 2008), strongly suggesting their competence in a metal depleted environment. However, the function of numerous CAs in diatoms are still speculative and need to be identified at the molecular level.

\section{Importance of Carbonic Anhydrases in Algal $\mathrm{CO}_{2}$-Concentrating Mechanisms}

CAs catalyze the reversible reaction of $\mathrm{CO}_{2}$ hydration and thus their physiological function deeply relies on the local $\mathrm{pH}$ of the individual cellular location of the enzymes. Recent investigations revealed that RubisCO and $\beta$-type CAs (denoted as PtCA1 and PtCA2) are located in the pyrenoid of $P$. tricornutum and that these CAs are induced remarkably at low $\mathrm{CO}_{2}$ concentrations. The biochemical composition of the pyrenoid in algae is not well known, but similarities have been demonstrated among a limited number of proteins localized in the pyrenoids of eukaryotic algae. CA in the areas of pyrenoids are likely responsible for efficient formation of $\mathrm{CO}_{2}$ at the proximity of RubisCO in the pyrenoid. This process is probably affected by the redox condition in the stroma via thioredoxins (Trxs) in response to the light intensities and the oxygen concentrations, in order to ensure optimal energy flow and carbon fixation under changing environmental conditions (described in the following section).

The occurrence and the function of external CAs in microalgae have been discussed controversially. It has been postulated that CA activity in the periplasmic space may enhance $\mathrm{CO}_{2}$ consumption in alkaline environments, where the major carbon source is $\mathrm{HCO}_{3}{ }^{-}$. However, silencing of the external CA CAH1 in C. reinhardtii did not alter cells to a high $\mathrm{CO}_{2}$-requiring phenotype (Van and Spalding 1999), although the possibility still remains that the other external CA, CAH8 
may complement the function of CAH1 (Ynalvez et al. 2008). In marine photoautotrophs, the importance of external CAs has been stressed as well as that of acidification at the periplasmic unstirred layer, a space surrounding cells where cellular activities of $\mathrm{H}^{+}$and $\mathrm{OH}^{-}$pump are the predominant factor to determine $\mathrm{pH}$ (Milligan and Morel 2002). As aforementioned, high salinity and alkalinity of seawater tend to remove $\mathrm{CO}_{2}$ from cell exterior which may force cells to invest energy in pumping $\mathrm{HCO}_{3}^{-}$, while $\mathrm{CO}_{2}$ uptake via external CA is energetically less expensive. In fact, in the dinoflagellates Prorocentrum micans and Lingulodinium polyedrum, external CAs have been shown to be essential (Nimer et al. 1999; Lapointe et al. 2008). However, it is also known that external CAs are absent in some marine microalgae (Danson et al. 2004). In marine diatoms, the occurrence of external CAs can be inconsistent even in a single species (John-Mckay and Colman 1997).

In contrast, intracellular CAs are likely an essential component of the CCM and of photosynthesis under $\mathrm{CO}_{2}$ limitations. For example, knock-out of the internal $\beta$-CA gene icfA (later renamed as $c c a A$ ) in cyanobacteria resulted in a high $\mathrm{CO}_{2}$-requiring phenotype (Fukuzawa et al. 1992). Similarly, a mutation of $\mathrm{Cah} 3$ caused a high $\mathrm{CO}_{2-}$ requiring phenotype in $C$. reinhardtii (Funke et al. 1997). The respective CAs have been localized in the carboxysome shell in cyanobacteria (Long et al. 2007) and the thylakoid lumen in $C$. reinhardtii (Karlsson et al. 1998). They are believed to supply $\mathrm{CO}_{2}$ from accumulated $\mathrm{HCO}_{3}{ }^{-}$at the cellular proximity of RubisCO (Funke et al. 1997; Raven 1997; Van and Spalding 1999). In diatoms, internal CAs have been demonstrated to be essential on the physiological level. In P. tricornutum, the highly permeable CA inhibitor ethoxyzolamide (EZA) severely suppressed the operation of high-affinity photosynthesis, whereas the weakly permeable inhibitor acetazolamide (AZA) had little effect (Satoh et al. 2001), strongly suggesting that the role of external CA is rather small compared to that of internal CAs.
Table 18.3. Carbonic anhydrases and their localization in P. tricornutum.

\begin{tabular}{lll}
\hline Name & Class & Location \\
\hline CA-I & $\alpha$ & PPC \\
CA-II & $\alpha$ & PPC \\
CA-III & $\alpha$ & CER \\
CA-IV (PtCA1) & $\beta$ & Pyrenoid \\
CA-V (PtCA2) & $\beta$ & Pyrenoid \\
CA-VI & $\alpha$ & CER \\
CA-VII & $\alpha$ & CER \\
CA-VIII & $\gamma$ & Mitochondria \\
CA-IX & $\gamma$ & N.D. \\
CA-X & $\zeta$ & N.D. \\
\hline
\end{tabular}

Data are summarized from Tachibana et al. (2011)

$P P C$ periplastidal compartment, $C E R$ chloroplastic endoplasmic reticulum, N.D. not detected

\section{E. Localizations and Functions of Diatom Carbonic Anhydrases}

As summarized in Table 18.3, the individual location of diatom CAs has been extensively investigated in the pennate marine diatom, P. tricornutum (Tanaka et al. 2005; Kitao et al. 2008; Kitao and Matsuda 2009; Tachibana et al. 2011) and the centric diatom, T. pseudonana (Tachibana et al. 2011). There are genes encoding $5 \alpha$-, $2 \beta$-, and $2 \gamma$-type CAs in the genome of P. tricornutum and these subclasses are located in specific organelles depending on the subtype (Tachibana et al. 2011). All putative $\alpha$-CAs were located in the four-layered chloroplast envelopes, two $\beta$-CAs were within the pyrenoid, and one putative $\gamma$-CA, CA-VIII, was found in the mitochondria (Tanaka et al. 2005; Kitao et al. 2008; Tachibana et al. 2011). The remaining $\gamma$-CA candidate, CA-IX most likely is also located in the mitochondria (Nawary and Matsuda, unpublished). A total of 13 CA candidate genes have been identified in the genome of T. pseudonana (encoding $3 \alpha-, 5$ $\gamma$-, $4 \delta$-, $1 \zeta$-type enzymes). Nine CAs out of these 13 candidates have recently been localized. That is, $\alpha-\mathrm{CA} 1$ was localized in the stroma; $\gamma$-CA1, 3 , and 4 were in the mitochondria; $\gamma$-CA2 was in the cytosol; $\delta$-CA 1,2 , and 3 were respectively localized in the periplasmic space, mitochondria, and 
periplastidal compartment; $\zeta$-CA1 was localized at the periplasmic space (Tachibana et al. 2011; Samukawa et al. 2014). However, the localization of the other CAs awaits further studies. Nonetheless, the CA localization data in T. pseudonana displayed a significant diversity in CA localization in diatoms, strongly suggesting the diversity of the mode of DIC flux control in diatoms (Samukawa et al. 2014).

In $P$. tricornutum, five $\alpha$-CAs that are located in the chloroplast envelope system, are transcriptionally active and are expressed independently of the $\mathrm{CO}_{2}$ concentrations (Tachibana et al. 2011). This suggests that these CAs may work constantly to control the permeation of DIC from the cytoplasm to the stroma and vice versa. This finding may be strongly related to the occurrence of DIC channels in the envelope membranes and potentially different $\mathrm{pH}$ values in the compartment between the plastid envelope membranes, although the details are yet clear. Two pyrenoidal $\beta$-type CAs, PtCA1 and PtCA2, are exclusive $\mathrm{CO}_{2}$-responsive CAs in $P$. tricornutum, being de-repressed under low $\mathrm{CO}_{2}$ conditions (Harada and Matsuda 2005; Harada et al. 2005; Tachibana et al. 2011), in which the pyrenoid would constitute a strong driving force to direct $\mathrm{CO}_{2}$ to RubisCO for fixation. During such a physiological state - where $\mathrm{CO}_{2}$ is efficiently directed to RubisCO under $\mathrm{CO}_{2}$ limitations the input of DIC from the bulk medium should also be ensured by specific transporters (as described above).

The putative $\gamma$-CAs in the mitochondria studied so far are not related to photosynthetic carbon fixation, and the activity of $\gamma$-CA candidate is not confirmed so far. Their function is thus so far obscure, but their mitochondrial localization strongly suggests that some of these proteins are involved in anaplerotic processes to provide $\mathrm{HCO}_{3}{ }^{-}$to phosphoenol pyruvate or pyruvate in the mitochondria (Giordano et al. 2003).

\section{F. Is There a $\mathrm{C}_{4}$ Metabolism in Diatoms?}

$\mathrm{A} \mathrm{C}_{4}$-type biochemical CCM was shown to be a part of the diatom CCM in the relatively large marine centric diatom, Thalassiosira weissflogii (Reinfelder et al. 2000, 2004; Roberts et al. 2007b; McGinn and Morel 2008). However, radio tracer experiments for photosynthetic products revealed in another centric species, T. pseudonana, the absence of a transient increase in $\mathrm{C}_{4}$ metabolites prior to the increment of 3-PGA, indicating that this centric diatom fixes $\mathrm{CO}_{2}$ by a $\mathrm{C}_{3}$-based metabolism. It is thought that the occurrence of $\mathrm{C}_{4}$-type photosynthesis might be limited to particular species (Roberts et al. 2007b). Haimovich-Dayan et al. (2013) recently investigated gene silencing of the pyruvate orthophosphate dikinase (PPDK) gene in P. tricornutum cells and proposed that the $\mathrm{C}_{4}$ metabolism may not increase net $\mathrm{CO}_{2}$ fixation but rather helps the cells to dissipate excess light energy and to maintain $\mathrm{pH}$ homeostasis. Genes encoding carboxylating and decarboxylating enzymes exist in the genomes of $P$. tricornutum and T. pseudonana. In silico analyses of both $P$. tricornutum and T. pseudonana genome databases indicate that the decarboxylating enzymes phosphoenol pyruvate carboxykinase (PEPCK) and malic enzyme do not possess plastid targeting sequences (Kroth et al. 2008), and in fact, a recent localization study has shown the lack in the decarboxylation enzyme in the chloroplast of $T$. pseudonana (Tanaka et al. 2014). Moreover, there is no evidence so far for the presence of malate and/or oxaloacetate transporters in the plastid membranes (Kroth et al. 2008). Supply of oxaloacetate to intact chloroplast isolated from the diatom Odontella sinensis did not stimulate photosynthetic oxygen evolution (Wittpoth et al. 1998), also suggesting the potential import of oxaloacetate into the plastids of diatoms. It is interesting that $\mathrm{C}_{4^{-}}$ type diatoms like $T$. weissflogii still actively take up both $\mathrm{CO}_{2}$ and $\mathrm{HCO}_{3}{ }^{-}$at equal rates (Table 18.2) (Burkhardt et al. 2001). One explanation could be that $\mathrm{C}_{4}$-type diatoms might also employ active DIC uptakes, which consequently could provide a part of $\mathrm{CO}_{2}$ directly from the developed DIC pool to the Calvin cycle, constituting a hybrid-type, i.e., a biophysical and a biochemical CCM (McGinn and Morel 2008). 
The evolutionary driving force in diatoms to acquire a biochemical CCM in addition to the existing biophysical CCM is unknown. One of the possible explanations could be the extreme diversification of diatom cell sizes that might force the development of a redundant CCM system to overcome diffusion resistance of pooled DIC molecules (Matsuda et al. 2011). Alternatively (or simultaneously), it is also possible that both, biochemical and biophysical CCMs, may contribute to dissipation of light energy by consuming ATP. Of particular interest is that the biophysical CCM as well as the $\mathrm{C}_{4}$ system could be an efficient consumption system of ATP by cycling $\mathrm{CO}_{2}$ through uptake and leakage across the cytoplasmic membrane when pooled DIC is not fixed efficiently and light excitation pressure continuously closes the photosystems (Tchernov et al. 1997).

\section{G. Transcriptional Regulation of $\mathrm{CO}_{2}-$ Concentrating Mechanism Components}

Algal $\mathrm{CO}_{2}$ acquisition systems are regulated at the transcriptional level via $\mathrm{CO}_{2}$ concentrations. This phenomenon raises the intriguing question how algal cells sense the concentration of environmental $\mathrm{CO}_{2}$. Furthermore it is unclear how such control mechanisms within the algal CCM may influence net photosynthesis at increasing environmental $\mathrm{CO}_{2}$ concentrations, which are expected to occur in the future due to human activity.

Physiological aspects of the $\mathrm{CO}_{2}$ response of CCMs have been reported in cyanobacteria and green algae since the early 1980s (Marcus et al. 1983; Mayo et al. 1986; Dionisio-Sese et al. 1990; Sueltemeyer et al. 1991; Matsuda and Colman 1995a, b). In summary, two systems have been proposed: (i) In cyanobacteria, the critical controlling factor for overall CCM activity is the $\mathrm{CO}_{2} / \mathrm{O}_{2}$ ratio (Marcus et al. 1983) and the total amount of DIC in the medium (Mayo et al. 1986), but not the $\mathrm{pH}$ or individual DIC species (Mayo et al. 1986). This strongly suggests the participation of a photorespiratory pathway in transmitting the $\mathrm{CO}_{2}$ signal to gene expression in cyanobacteria (Marcus et al. 1983; Mayo et al. 1986). (ii) On the other hand, CCMs in the green algae Chlorella ellipsoidea and $C$. reinhardtii respond to $\mathrm{CO}_{2(\mathrm{aq})}$ in the medium rather than other DIC species or total DIC (Matsuda and Colman 1995b; Bozzo and Colman 2000). Furthermore, neither the internal DIC concentration nor the light intensity was correlated with the CCM expression levels in C. ellipsoidea, suggesting that a $\mathrm{CO}_{2}$ response mechanism in eukaryotic algae does not necessarily depend on metabolite feedback, but also includes more direct sensing mechanisms (Matsuda and Colman 1995b).

The metabolite signaling hypothesis in cyanobacteria is supported indeed, by the molecular evidence that a transcription factor of Synechocystis sp. PCC 6803, CmpR, which is the LysR family inducing factor of the $\mathrm{HCO}_{3}{ }^{-}$transporter operon cmpABCD, can bind directly to the promoter region of the cmpABCD operon and that binding is significantly stimulated in the presence of a physiological concentrations of 2-phosphoglycolate, the first product of oxygenase reaction by RubisCO (Omata et al. 2001; Nishimura et al. 2008). In eukaryotic algae, on the other hand, most of the molecular work on transcriptional controls of putative CCM components has been done with the green alga $C$. reinhardtii. The periplasmic CA gene Cahl in C. reinhardtii is a well known $\mathrm{CO}_{2}$-responsive gene and regulation of the promoter region of $\mathrm{Cahl}$ are governed by tandemly aligned enhancer and silencer regions on the promoter (Kucho et al. 1999). A zinc finger protein, CCM1/CIA5 was found to control the up-regulation of most of the low- $\mathrm{CO}_{2}$-inducible genes including $\mathrm{Cahl}$ and thus is considered to be a master regulator for $\mathrm{CO}_{2}$-responsive gene expressions (Fukuzawa et al. 2001; Xiang et al. 2001; Miura et al. 2002, 2004; Wang et al. 2005; Kohinata et al. 2008; Yamano et al. 2008). However, the key factor for capturing the $\mathrm{CO}_{2}$ signal in algae is unknown.

Similarly to green algae, the major determinant of the extent of CCM expression in P. tricornutum likely is the $\mathrm{CO}_{2(\text { aq) }}$ concentration in the medium rather than the $\mathrm{pH}$ value 

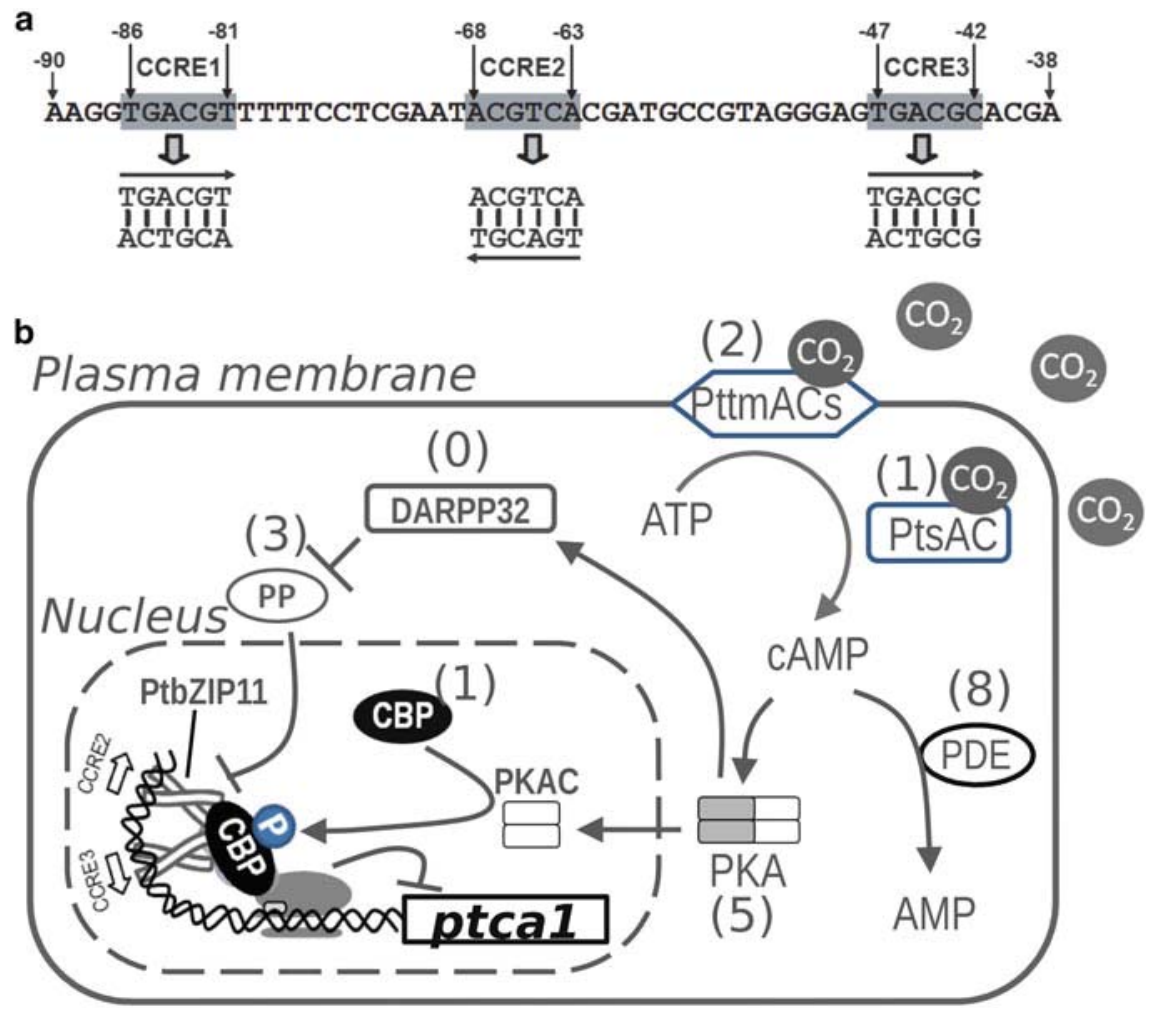

Fig. 18.3. The $\mathrm{CO}_{2}$ responsive ptcal promoter and the putative $\mathrm{CO}_{2}$ signaling pathway. (a) Structure of the core-regulatory region of the ptcal promoter with 3 CCRE elements (Redrawn from Ohno et al. 2012). (b) Putative $\mathrm{CO}_{2}$ signaling pathway predicted based upon the mammalian cAMP signaling cascade. PDE cAMP phosphodiesterase, $P K A$ protein kinase A, $P K A C$ C subunit of PKA, $P P$ protein phosphatase, $C B P$ CREB (cAMP binding protein) binding protein, $D A R P P$ dopamine-and cAMP-regulated phosphoprotein. Parentheses indicate the number of candidate genes in the P. tricornutum genome. So far, there is no known candidate for a functional analogue of DARPP. The model depicts the signaling route under high $\mathrm{CO}_{2}$ conditions, which may activate tmACs and/or sACs. PtbZIP11 binds to CCREs to form a repressor complex on the ptcal promoter.

or other DIC species (Matsuda et al. 2001). The number of known typical $\mathrm{CO}_{2}$ responsive molecules is still low in marine diatoms and the aforementioned PtCA1 and 2 enzymes have been the best model for molecular studies on the mechanisms of $\mathrm{CO}_{2}$ responses. The genes ptcal and ptca2 are known to be markedly de-repressed at the transcriptional level in response to a decrease in $\left[\mathrm{CO}_{2}\right]$ (Satoh et al. 2001; Harada et al. $2005,2006)$. The $\beta$-glucuronidase (GUS) reporter assay of the promoter region of ptcal (Pptcal) revealed that a relatively short sequence of up to $100 \mathrm{bps}$ upstream the transcription-start site plays a key role in $\mathrm{CO}_{2}$-responsive transcription, and that this region is rich in animal-type cAMP-response elements (Harada et al. 2006). Indeed, the ability of the cAMP analogue dibutyryl cAMP (dbcAMP) to mimic high $\mathrm{CO}_{2}$ conditions and to repress transcription of ptcas (Harada et al. 2006) disappears by impairing the Pptcal sequences (Harada et al. 2006). Further investigations have revealed that the critical $\mathrm{CO}_{2}$-responsive cis-element of Pptcal contains three analogous sequences TGACGT/C which are tandemly aligned in an invert direction within the core Pptcal sequence. These were denoted $\mathrm{CO}_{2} / \mathrm{cAMP}$ responsive elements (CCRE) 1, 2, and 3 (Ohno et al. 2012) (Fig. 18.3). The CCREs are the typical targets of mammalian ATF6type basic-ZIP-transcription factors such as cAMP-responsive-element-binding protein 
(CREB). Therefore the genome of $P$. tricornutum was screened for genes encoding potential ATF6-type-bZIP proteins based upon the well conserved DNA binding site of ATF6 with an adjacent leucine zipper motif (Ohno et al. 2012). As a result, one of the eight candidate bZIP proteins, denoted PtbZIP11, was found to bind to CCREs specifically (Ohno et al. 2012) (Fig. 18.3). These investigations clearly revealed that diatoms use cAMP signaling, which is perhaps similar to the mammalian system, to respond to ambient $\mathrm{CO}_{2}$ concentrations (Fig. 18.3). In fact, most of the genes involved in the typical mammaliantype cAMP signaling pathways have been identified in diatom EST databases (Fig. 18.3).

Adenylyl cyclase (AC) is known to serve as a sensor for inorganic carbon signals in a wide variety of living organisms from cyanobacteria, fungi, to mammals, except for higher plants (Chen et al. 2000; Klengel et al. 2005; Matsuda et al. 2011). In rat testis, the activity of soluble adenylyl cyclase (sAC) is modulated by $\mathrm{HCO}_{3}^{-}$and $\mathrm{pH}$, and this sAC is closely related to bacterial-type sACs (Chen et al. 2000). In cyanobacteria, indeed, the activities of sAC, CyaB1 (Anabaena sp.) and Cya1 (Synechocystis sp. PCC6803) were shown to be regulated by inorganic carbon (most probably by $\mathrm{CO}_{2}$ ) (Hammer et al. 2006). Cyclic AMP in cyanobacteria has been related to blue-light responses, the mating system, and cell division, but so far not to CCM regulation (Matsuda et al. 2011). In diatoms, there are also putative $\mathrm{CO}_{2}$-sensing ACs (one for soluble ACs and two for transmembrane-type ACs, tmAC1 and tmAC2 in $P$. tricornutum; there are two candidate tmACs in $T$. pseudonana), which were denoted PtsAC, PttmAC1, and PttmAC2, respectively, in $P$. tricornutum, and TptmAC1 and TptmAC2 in T. pseudonana (Matsuda et al. 2011). These ACs were suggested to be a part of $\mathrm{CO}_{2}$-sensing system in P. tricornutum, and in fact, a significant stimulation of AC activity in total lysates of $P$. tricornutum by DIC was observed, although the function of each AC yet has to be identified (Matsuda et al. 2011). CCM regulation in P. tricornutum is highly depending on light as well as on $\mathrm{CO}_{2}$ concentrations (Harada et al. 2005), strongly suggesting the occurrence of a crosstalk between the $\mathrm{CO}_{2}$-responsive cAMP-signaling pathway and light.

\section{Delivery Systems of $\mathrm{CO}_{2}$ to Rubis $\mathrm{CO}$ and $\mathrm{CO}_{2}$ Fixation}

The final step of the CCM perhaps cooperates deeply with the initial step of the Calvin cycle. The $\mathrm{CO}_{2}$-fixing enzyme, RubisCO in diatoms belongs to the Form I (red-type) enzyme (Badger et al. 1998); the activating mechanism has yet to be elucidated. RubisCO as well as CAs have been localized in diatom pyrenoids (Jenks and Gibbs 2000; Tachibana et al. 2011), strongly suggesting that the $\mathrm{CO}_{2}$ concentration is elevated in close proximity of RubisCO by the formation of $\mathrm{CO}_{2}$ from $\mathrm{HCO}_{3}{ }^{-}$catalyzed by CAs (Hopkinson et al. 2011). However, detailed mechanisms of $\mathrm{CO}_{2}$ supply to the Calvin cycle and regulations of the CCM and the Calvin cycle still have to be elucidated in diatoms.

\section{A. Biochemical Components of the Pyrenoid}

Pyrenoids have been studied on the morphological level, but their biochemical structure and function are still largely unknown. The morphology of the pyrenoid can be extremely diverse, but there is similarity in biochemical components associated with the pyrenoid in different species. In the green alga $C$. reinhardtii most of RubisCO protein is located in the pyrenoid (Lacoste-Royal and Gibbs 1987; Kuchitsu et al. 1988; Borkhsenious et al. 1998). Similarly, pyrenoids of Chlorella pyrenoidosa, Porphyridium cruentum, Euglena gracilis, and the Anthocerotae ferns were identified as RubisCO aggregates (Mckay and Gibbs 1989, 1990; Osafune et al. 1990; Vaughn et al. 1990). Besides RubisCO, nitrate reductase (NR), RubisCO activase, and the $\mathrm{LCIB} / \mathrm{C}$ complex were also localized in the pyrenoid of $C$. reinhardtii (Lopez-Ruiz et al. 1985; McKay et al. 1991; Yamano et al. 2010). In C. reinhardtii, CAH3 was also 
found in the lumen of the pyrenoid-penetrating thylakoid (Karlsson et al. 1998). The function of the LCIB/C complex is not clear yet, but impairment of LCIB results in a lethal phenotype under ambient $\mathrm{CO}_{2}$, while the cells survive under reduced $\mathrm{CO}_{2}$ concentrations. This indicates its vital function under moderate $\mathrm{CO}_{2}$ starvation. It further indicates that another high-affinity system may participate under severer $\mathrm{CO}_{2}$ starvation conditions (Wang and Spalding 2006). LCIB homologues were also found in many eukaryotic algae including diatoms (Yamano et al. 2010), suggesting that this protein is conserved in pyrenoids across species. It has also been reported earlier that ribulose-5-phosphate isomerase and ribulose-5-phosphate kinase activities were detected in the pyrenoidal fraction of the giant green alga Eremospheaera viridis (Holdsworth 1971), suggesting that a part of reactions in the Calvin cycle may occur in the pyrenoid.

In P. tricornutum, the structure of the pyrenoid has been reported as a lens-shaped body residing in the central part of the stroma. Two layered thylakoid membranes are known to penetrate in the center of the pyrenoid (Fig. 18.2) (Jenks and Gibbs 2000). RubisCO was localized in the pyrenoid of P. tricornutum (Jenks and Gibbs 2000), together with two $\beta$-type CAs (PtCA1 and PtCA2) and two plastidic fructose-1,6-bisphosphate aldolases (FBAs) (Allen et al. 2012). PtCA1 and 2 are the first CAs to be found in the pyrenoid, although this localization already has been proposed earlier in algae with CCMs (Pronina and Semenenko 1984; Kuchitsu et al. 1991). PtCA1 and 2 are known to form large clumped particles within the stroma (Tanaka et al. 2005; Kitao et al. 2008) and this particle formation was demonstrated to be driven by an amphipathic helix at the C-terminal ends (Kitao and Matsuda 2009). PtCAs are not uniformly distributed within the pyrenoid. Their location appears to be limited to the central part of the lens-shaped pyrenoid (Tachibana et al. 2011), suggesting a layered structure within the pyrenoid (Matsuda et al. 2011). It should be noted that the LCIB/C hetero-hexamer apparently surrounds the pyrenoid structure in C. reinhardtii (Yamano et al. 2010), presumably shielding the pyrenoid from $\mathrm{CO}_{2}$ leakage or recapturing leaking $\mathrm{CO}_{2}$ from the pyrenoid in cooperation with the stromal CAH6 (Mitra et al. 2004; Yamano et al. 2010). The layered structure of the pyrenoid in P. tricornutum may also be important to avoid leakage of $\mathrm{CO}_{2}$. Co-localization of fructose bisphosphatases, FBAC1 and FBAC5 with PtCA1 in the pyrenoid (Allen et al. 2012) implies that the initial part of $\mathrm{CO}_{2}$ input and the first step to hexose output of the Calvin cycle may occur in the pyrenoid. Interestingly FBA is one of the primary rate limiting factors of the Calvin cycle in higher plants and also PtCA1 seems to play a major role in supplying substrate to RubisCO. This strongly suggests that diatom pyrenoids play a central role in controlling carbon metabolism within and around the Calvin cycle.

\section{B. Redox Regulation of $\mathrm{CO}_{2}$ Acquisition and Fixation Systems in the Stroma}

Redox states play an important role in plastids of higher plants regulating photosynthetic carbon reduction in the Calvin cycle, nitrogen metabolism, fatty acid biosynthesis, carbohydrate storage and translation (Meyer et al. 2009). Chloroplasts of algae and land plants generally possess the ferredoxin $(\mathrm{Fd}) /$ thioredoxin (Trx) system (Buchanan and Balmer 2005). The Arabidopsis genome contains at least $12 \operatorname{Trx}$ isoforms, which are grouped into seven subfamilies denoted Trx $f, h, m, o, x, y$ and $z$ based on their primary structures (Mestres-Ortega and Meyer 1999; Lemaire and Miginiac-Maslow 2004; Arsova et al. 2010). Of these, $\operatorname{Trxs} f, m, x, y$ and $z$ are known to be typical chloroplast proteins (Schuerman and Jacquot 2000; Collin et al. 2003; Lemaire et al. 2003; Arsova et al. 2010). In chloroplasts of higher plants and green algae, the function of Trx seems to be very extensive, directly targeting more than 300 proteins, including numerous plastidic factors of unknown function (Motohashi et al. 2001; Balmer et al. 2003; Lemaire et al. 2004). In contrast, the function of plastidic Trxs in diatoms seems to be rather limited. 
Eight genes encoding a set of Trxs have been identified in the genome of $P$. tricornutum, and at least three Trx candidates $(f, m$, and $y)$ are located in the chloroplast together with a ferredoxin-thioredoxin reductase (FTR) gene, essential for Trx reduction via the electron transport chain (Weber et al. 2009). However, none of the several key enzymes in the Calvin cycle, which are under redox regulation in higher plants, appear to be regulated by Trxs in diatoms (Liaud et al. 2000; Michels et al. 2005; Kroth et al. 2008; Weber et al. 2009), with the so far only exception of the fructose-1,6-bisphosphatase (FBPase) and the phosphoglycerate kinase (Michels et al. 2005; Bosco et al. 2012). It is thus likely that the plastidic Trx systems in diatoms and in other chromist algae have undergone a unique functional specialization.

Activities of CCMs in marine diatoms are controlled by light and by environmental $\mathrm{CO}_{2}$ concentrations (Colman and Rotatore 1995; Johnston and Raven 1996; Matsuda et al. 2001, 2002), strongly indicating the importance of $\mathrm{CCM}$ regulation in response to the availability of light and $\mathrm{CO}_{2}$. As aforementioned, PtCA1 and PtCA2 in P. tricornutum presumably take a vital role in supplying $\mathrm{CO}_{2}$ to RubisCO in the pyrenoid, thus controlling the initial reaction of the Calvin cycle. A recent study has demonstrated that both PtCA1 and PtCA2 are targets of plastidic Trxm and Trx $f$ of $P$. tricornutum, and are activated via reduction by DTT (Kikutani et al. 2012). The presence of these Trxs significantly stimulated the efficiency of the reductive activation of PtCAs (Kikutani et al. 2012). Interestingly, PtCA1 requires Trx to be stimulated to its maximum activity, while PtCA2 only revealed stimulation of the efficacy of reductive activation (Kikutani et al. 2012). In P. tricornutum Trx targets two Cys residues (105 and 166 in PtCA1; 102 and 163 in PtCA2; relative to the mature $\mathrm{N}$-termini) and disulfide formation of these two Cys residues is specifically regulated by oxygen concentrations above atmospheric levels (Kikutani et al. 2012). Interestingly, these Cys residues are not conserved in plastidic $\beta$-CAs in green algae, red algae, and higher plants (Kikutani et al. 2012). It was shown that the disulfide bond (such as between Cys 105 and 166 in PtCA1) is critical for regulation of PtCA activity, being a unique characteristic in $\beta$-CAs in chromists, opisthokonts, and bacteria and suggesting that this particular redox moiety was obtained via an HGT event (Kikutani et al. 2012). The redox potentials of PtCA1 and PtCA2 were determined to be around $-370 \mathrm{mV}$ (unpublished data), a value which allows reduction exclusively by the reduction side of the photosystem I (PSI) via Fd (Kikutani et al. 2012). A disulfide is formed between these Cys residues specifically by molecular oxygen above atmospheric levels to inactivate PtCAs, and none of other oxidants which commonly occur in the chloroplast (such as oxidized glutathione, dehydro-ascorbate, and $\mathrm{H}_{2} \mathrm{O}_{2}$ ), may substitute this function of molecular oxygen (Kikutani et al. 2012). These results strongly suggest that the $\mathrm{CO}_{2}$ acquisition system, and not the fixation system, is the target of redox control via Trxs in the diatom plastid, and that the function of the pyrenoid is under the control of light-driven reduction mediated by Trx and molecular oxygen generated in PSII (Fig. 18.4). This implies that activities of PSI and PSII compete for control of the redox state of pyrenoid-forming CAs. Thus, oxygen concentrations above the atmospheric level efficiently inactivate PtCAs by forming a disulfide across the active center (Kikutani et al. 2012), but electrons from the reducing side of the PSI regularly cleave this disulfide, regulating the activity of PtCAs in response to oxygen concentration and light intensity. This strongly suggests that the function of the pyrenoidal CAs is fine-tuned on the posttranslational level reflecting the balance of energy distribution between PSI and PSII.

\section{Carbon Metabolism Relating to Photosynthesis and Respiration}

The Calvin cycle is the central reaction in the plastid and produces hexoses, consuming ATP and NADPH derived from the light 


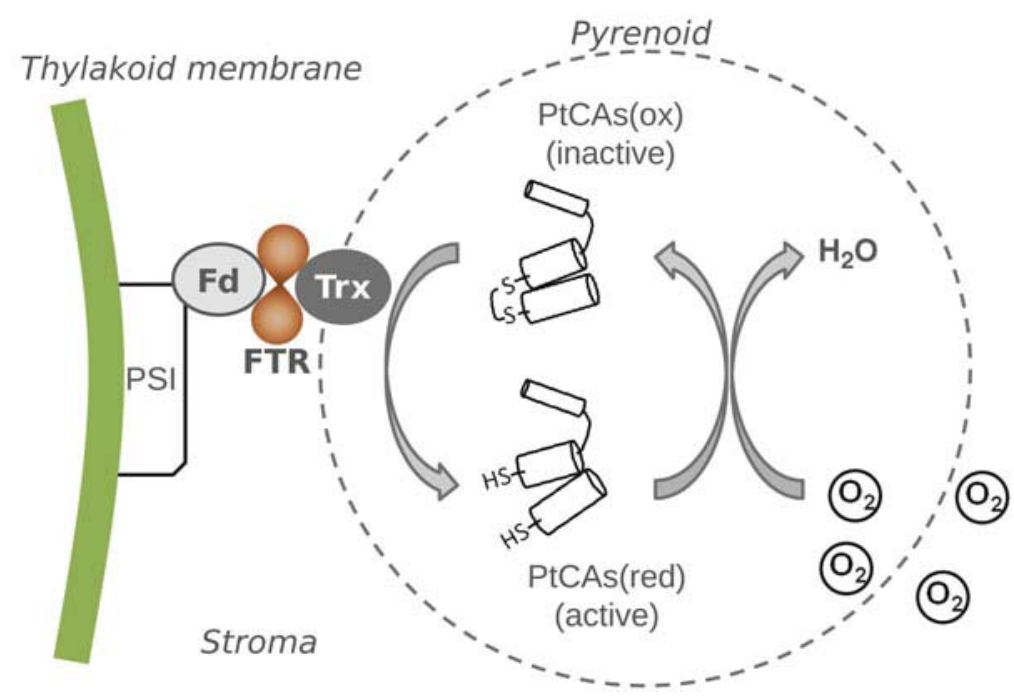

Fig. 18.4. A schematic drawing of the redox regulation of affecting structure and activity of PtCAs via chloroplastic Trx. Electrons derived from the reducing (stromal) side of photosystem I (PSI) are transferred to the ferredoxin $(\mathrm{Fd})$ - thioredoxin ( Trx) reductase complex, which constitute an electron transfer metabolon with Fd and Trx. Reduced Trx then reduces the target protein (PtCAs in the pyrenoid), cleaving the intramolecular disulfide bond to activate PtCAs. The reduced active form of PtCAs is oxidized by molecular oxygen above atmospheric levels which originates from active PSII.

reactions of the photosystems. Carbon dioxide is the major sink of light-driven ATP production and reducing power. However, amino acid synthesis including nitrogen and sulfur assimilation, photorespiration, and any other ATP/NADPH consuming process can also be an important sink for light energy. Moreover, the Calvin cycle is an essential process converting the length of carbon skeletons between $\mathrm{C}_{3}-\mathrm{C}_{7}$, thereby interfacing with several other biosynthesis pathways such as glycolysis, pentose phosphate pathway, a part of gluconeogenesis, as well as fatty acid and amino acid biosynthesis. The reactions of the Calvin cycle and the adjacent carbon metabolism have therefore to be highly regulated to avoid short circuits of energy and substrate consumption. In diatoms, the essential regulatory enzymes of these processes are redundant and their relations and regulations are still largely unclear.

\section{A. RubisCO and the Calvin Cycle}

The main pathway for photosynthetic carbon fixation in photosynthetic organisms is the
Calvin cycle formally termed reductive pentose phosphate pathway. The RubisCO catalyses the first step in carbon fixation and consists of two subunits, the small and the large subunit. In contrast to land plants, both RubisCO subunits are encoded on the plastid genome in P. tricornutum and T. pseudonana (Oudot-Le Secq et al. 2007). It is noteworthy that, despite several nuclear-encoded genes are related to those in green algae, there is no RubisCO activase encoded in the genomes of $P$. tricornutum and T. pseudonana (Kroth et al. 2008), suggesting that diatom formI RubisCO is under the control of unknown activation factors similar to that of red algae. A recent study demonstrated that an ATPase-associated various cellular activities $\left(\mathrm{AAA}^{+}\right)$type protein, $\mathrm{CbbX}$, is the activase of red-type formI RubisCO in the purple bacterium, Rhodobacter sphaeroides (Mueller-Cajar et al. 2011). Interestingly, P. tricornutum and T. pseudonana possess putative CbbX genes in both plastidic and nuclear genomes (Chishiro, Kikutani, Matsuda, unpublished). The function of these gene products await to be studied. 
All further Calvin cycle enzymes are encoded by the nuclear genomes. The two subsequent enzymatic steps after caryboxylation, the reduction to carbohydrates, are catalysed by a plastid targeted phosphoglycerate kinase (PGK) and a glyceraldehyde3-phosphate dehydrogenase (GAPDH). In these two cases, only single plastidic isoenzymes have been identified in P. tricornutum and T. pseudonana. Interestingly, for the following reactions, the regeneration of the $\mathrm{CO}_{2}$ acceptor ribulose-1,5-bisphosphate, multiple nuclear-encoded and plastid-targeted isoforms of enzymes are found: for instance in $P$. tricornutum there are three fructose-1, 6-bisphosphate aldolase (FBA) isoforms (two in T. pseudonana), four fructose-1, 6-bisphosphatase (FBPase) isoforms (two in T. pseudonana), two triosephosphate isomerase (TPI) isoforms (one in T. pseudonana) and two transaldolase (TAL) isoforms (three in T. pseudonana) (Gruber et al. 2009). This multitude of isoenzymes may be a result of endosymbiotic processes (see above); however, the reason why the cells contain different isoenzymes in the same compartment remains unclear. This is especially interesting in the case of the FBPases, as two of the isoenzymes are redox-regulated, while the other two enzymes apparently are not (Gruber et al. 2009). One possible explanation could be the formation of regulatory hetero-oligomeric complexes. The other plastidic Calvin cycle enzymes ribose5-phosphate isomerases (RPI), ribulosephosphate epimerases (RPE) and transketolases (TKL), again, only appear as single enzymes. Interestingly, although a gene for a sedoheptulose-1,7-bisphosphatase (SBPase) is present in the diatom genomes, the respective protein does not possess a plastidic presequence, indicating that it is a cytosolic enzyme, which is supported by experimental evidence (Gruber et al. 2009). It remains yet unclear what the actual function of the cytosolic SBPase of diatoms could be. So far cytosolic SBPases are unknown in photosynthetic eukaryotes, but present in some non-photosynthetic organisms like ciliates, kinetoplastids and ascomycetes
(Rogers and Keeling 2004; Teich et al. 2007). Possibly, the cytosolic diatom SBPase is a part of a modified oxidative pentose phosphate pathway (OPP), which in diatoms has been removed completely from the chloroplast and which is situated in the cytosol (Gruber et al. 2009).

Oxidative pentose phosphate pathways can be found in plants and green algae in the cytosol as well as in the plastids. These pathways are mainly used for the generation of NADPH and ribose-5-phosphate and erythrose-4-phosphate as substrates for anabolic pathways. In isolated plastids of the diatom Odontella sinensis, no glucose-6phosphate dehydrogenase (GPDH) and 6-phosphogluconate dehydrogenase (PGDH) activity was detectable (Michels et al. 2005), and only cytosolic isoforms of GPDH and PGDH were identified in other diatoms (Kroth et al. 2008), leading to the suggestion that the OPP in diatoms might be generally restricted to the cytosol (Wilhelm et al. 2006). Rather unexpected was also the finding of a PGDH in the periplastidic space of P. tricornutum (Gruber et al. 2009). During the reaction from gluconate-6-P to ribulose5-P, the GPDH releases $\mathrm{CO}_{2}$ and thus could potentially increase the $\mathrm{CO}_{2}$ concentration in the periplastidic space. It is unclear yet, whether this reaction might be involved in the $\mathrm{CCM}$ in diatoms.

\section{B. Other $\mathrm{CO}_{2}$-Fixing Enzymes in Diatoms}

Annotation of the diatom genomes revealed a number of surprises as several genes have been identified of which the deduced proteins may be involved in $\mathrm{CO}_{2}$ fixation (Kroth et al. 2008). For instance two PEP carboxylases, which in $\mathrm{C}_{4}$ plants are involved in pre-fixation of $\mathrm{CO}_{2}$, have been identified in the genome of $P$. tricornutum. One of these PEP carboxylases is located in the mitochondria, while the second enzyme apparently is located in the periplastidic space of the plastids (Ewe, Gruber, Kroth, unpublished). Two pyruvate carboxylases, enzymes that usually are involved in gluconeogenesis, also have been discovered. One of them 
is located in the mitochondria, the other in the plastids. All of these enzymes could be involved in a biochemical CCM, however, most of them are separated from the RubisCO by several membranes, thus fixed carbon would have to be transported actively across several membranes. Furthermore no plastidic decarboxylase has yet been identified that may allow a release of the bound $\mathrm{CO}_{2}$ in close proximity to RubisCO. Reinfelder et al. (2000) found that phosphoenol pyruvate carboxykinase (PEPCK) activity co-localizes with RubisCO activity in isolated plastid-enriched fractions of $T$. weissflogii and concluded that decarboxylation occurred within the plastids, however, all decarboxylases identified so far are not located in the plastids: the PEPCK and two malic enzymes are located in the mitochondria. This of course does not exclude the possibility of occurrences of a plastidic decarboxylase, which simply might not be identified yet, due to lacking sequence similarity.

\section{Photorespiration}

In addition to its carboxylating activity, the RubisCO may also function as an oxygenase by fixing molecular oxygen at the same active site as $\mathrm{CO}_{2}$, thus splitting the substrate ribulose-1,5-bisphosphate into 2-phosphoglycolate (2PG) and 3-PGA. This oxygenase reaction is the first step of the photorespiratory pathway and is known to be an essential process dissipating light excitation energy in the photosystems when $\mathrm{CO}_{2}$ supply is limited and/or under high light irradiation (Kozaki and Takeba 1996). In plants with $\mathrm{C}_{4}$ metabolism and in microalgae possessing $\mathrm{CCMs}$, photorespiration does not occur even under atmospheric $\mathrm{CO}_{2}$ concentrations or under high light conditions, where photorespiration is unavoidable in $\mathrm{C}_{3}$-type plants. In diatoms, there are a few reports describing the occurrence of photorespiration under ambient conditions (Parker et al. 2004; Roberts et al. 2007a), suggesting that the diatom photorespiration operates even under the operation of the CCM. There seems to be a set of photorespiratory genes present in the genome of diatoms according to the DiatomCyc database (see Fabris et al. 2012; http://akongo.psb.ugent.be/), suggesting that the photorespiratory carbon oxidation cycle (PCOC) is the major pathway to recycle phosphoglycolate in diatoms (Armbrust et al. 2004; Bowler et al. 2008). In cyanobacteria, glycolate oxidation is found to be catalyzed by bacterial-type of glycolate dehydrogenase (GDH) instead of the plant-type glycolate oxidase (GOX) (Eisenhut et al. 2006). This oxygenindependent glycolate oxidation is also found in several groups of eukaryotic algae (like Chlorophyceae, Prasinophyceae, Cryptophyceae, and Bacillariophyceae) in contrast to the plant-type, oxygen-dependent pathway in Chrysophyceae, Eustigmatophyceae, Raphidophyceae, Xanthophyceae, and Rhodophyceae (Suzuki et al. 1991). Interestingly, some diatoms apparently possess two genes for both GOX and GDH (Kroth et al. 2008). A set of these enzymes revealed typical peroxisome-targeting signals at their C-termini, while the other enzymes seem to be equipped with mitochondrial targeting sequences, suggesting that glycolate oxidation may occur in these two organelles (Kroth et al. 2008).

A genome-based study by Kroth et al. (2008) suggested that PCOC occurs mainly in the mitochondria and glycolate is also integrated into the glyoxylate pathway via malate synthase in the peroxisome. Another alternative pathway of glycolate metabolism is the tartronic semialdehyde pathway. The existence of this pathway in diatoms (Kroth et al. 2008), originaly identified in cyanobacteria (Eisenhut et al. 2006), is suggested by precedential biochemical studies with T. pseudonana and Cylindrotheca fusiformis (Paul and Volcani 1974, 1976). It is also pointed out that so far no gene for the glycerate kinase (GK), an enzyme of the last step of PCOC, which forms 3-PGA, has yet been identified (Kroth et al. 2008). This strongly suggests that PCOC in diatoms would not result in recycling 3-PGA for fixation by the Calvin cycle, but rather supplying glycine and serine (Kroth et al. 2008). 


\section{Acknowledgements}

This work was supported by Grant-in-Aid for Scientific Research B (grant no. 24310015 to Y. M.), by Grant-in-Aid for Challenging Exploratory Research (grant no. 24651119 to Y. M.) from the Japan Society for the Promotion of Science (JSPS), by MEXT-Supported Program for the Strategic Research Foundation at Private Universities (2010-2014), by the Program for Research on Halophilic Organism of the Salt Science Research Foundation (grant no. 06B02 to Y. M.), and by the Steel Industry Foundation for the Advancement of Environmental Protection Technology to Y. M. PGK is grateful for financial support by the German Research Foundation (DFG), grant KR1661/7-1, the German Israeli Foundation (GIF), the University of Konstanz, and is thankful to A. Gruber and J. Hentschel for providing an unpublished electron micrograph.

\section{References}

Allen AE, Dupont CL, Obornik M, Horák A, NunesNesi A, McCrow JP, Zheng H, Johnson DA, Hu H, Fernie AR, Bowler C (2011) Evolution and metabolic significance of the urea cycle in photosynthetic diatoms. Nature 473:203-207

Allen AE, Moustafa A, Montsant A, Eckert A, Kroth PG, Bowler C (2012) Evolution and functional diversification of fructose bisphosphate aldolase genes in photosynthetic marine diatoms. Mol Biol Evol 29:367-379

Alterio V, Langella E, Viparelli F, Vullo D, Ascione G, Dathan NA, Morel FMM, Supuran CT, De Simone G, Monti SM (2012) Structural and inhibition insights into carbonic anhydrase CDCA1 from the marine diatom Thalassiosira weissflogii. Biochimie 94:1232-1241

Armbrust EV, Berges JA, Bowler C, Green BR, Martinez D, Putnam NH, Zhou S, Allen AE, Apt KE, Bechner M, Brzezinski MA, Chaal BK, Chiovitti A, Davis AK, Demarest MS, Detter JC, Glavina T, Goodstein D, Hadi MZ, Hellsten U, Hildebrand M, Jenkins BD, Jurka J, Kapitonov VV, Kröger N, Lau WW, Lane TW, Larimer FW, Lippmeier JC, Lucas S, Medina M, Montsant A, Obornik M, Parker MS, Palenik B, Pazour GJ, Richardson PM, Rynearson TA, Saito MA, Schwartz DC, Thamatrakoln K, Valentin K, Vardi A, Wilkerson FP,
Rokhsar DS (2004) The genome of the diatom Thalassiosira pseudonana: ecology, evolution, and metabolism. Science 306:79-86

Arsova B, Hoja U, Wimmelbacher M, Greiner E, Üstün S, Melzer M, Petersen K, Lein W, Börnke F (2010) Plastidial thioredoxin $z$ interacts with two fructokinase-like proteins in a thiol-dependent manner: evidence for an essential role in chloroplast development in Arabidopsis and Nicotiana benthamiana. Plant Cell 22:1498-1515

Ast M, Gruber A, Schmitz-Esser S, Neuhaus HE, Kroth PG, Horn M, Haferkamp I (2009) Diatom plastids depend on nucleotide import from the cytosol. Proc Natl Acad Sci U S A 106:3621-3626

Badger MR, Andrews TJ, Whitney SM, Ludwig M, Yellowlees DC, Leggat W, Price GD (1998) The diversity and coevolution of RubisCO, plastids, pyrenoids, and chloroplast-based $\mathrm{CO}_{2}$-concentrating mechanisms in algae. Can J Bot 76:1052-1071

Badger MR, Hanson D, Price GD (2002) Evolution and diversity of $\mathrm{CO}_{2}$-concentrating mechanisms in cyanobacteria. Funct Plant Biol 29:183-194

Balmer Y, Koller A, del Val G, Manieri W, Schürmann P, Buchanan BB (2003) Proteomics gives insight into the regulatory function of chloroplast thioredoxins. Proc Natl Acad Sci U S A 100:370-375

Borkhsenious ON, Mason CB, Moroney JV (1998) The intracellular localization of ribulose-1,5bisphosphate carboxylase/oxygenase in Chlamydomonas reinhardtii. Plant Physiol 116:1585-1591

Bosco MB, Aleanzi MC, Iglesias AA (2012) Plastidic phosphoglycerate kinase from Phaeodactylum tricornutum: on the critical role of cysteine residues for the enzyme function. Protist 163:188-203

Bowler C, Allen AE, Badger JH, Grimwood J, Jabbari K, Kuo A, Maheswari U, Martens C, Maumus F, Otillar RP, Rayko E, Salamov A, Vandepoele K, Beszteri B, Gruber A, Heijde M, Katinka M, Mock T, Valentin K, Verret F, Berges JA, Brownlee C, Cadoret JP, Chiovitti A, Choi CJ, Coesel S, De Martino A, Detter JC, Durkin C, Falciatore A, Fournet J, Haruta M, Huysman MJ, Jenkins BD, Jiroutova K, Jorgensen RE, Joubert Y, Kaplan A, Kröger N, Kroth PG, La Roche J, Lindquist E, Lommer M, MartinJezequel V, Lopez PJ, Lucas S, Mangogna M, McGinnis K, Medlin LK, Montsant A, Oudot-Le Secq MP, Napoli C, Obornik M, Parker MS, Petit JL, Porcel BM, Poulsen N, Robison M, Rychlewski L, Rynearson TA, Schmutz J, Shapiro H, Siaut M, Stanley M, Sussman MR, Taylor AR, Vardi A, von Dassow P, Vyverman W, Willis A, Wyrwicz LS, Rokhsar DS, Weissenbach J, Armbrust EV, Green BR, Van de Peer Y, Grigoriev IV (2008) The Phaeodactylum genome reveals the evolutionary history of diatom genomes. Nature 456:239-244 
Bozzo GG, Colman B (2000) The induction of inorganic carbon transport and external carbonic anhydrase in Chlamydomonas reinhardtii is regulated by external $\mathrm{CO}_{2}$ concentration. Plant Cell Environ 23:1137-1144

Buchanan BB, Balmer Y (2005) Redox regulation: a broadening horizon. Annu Rev Plant Biol $56: 187-220$

Bullmann L, Haarmann R, Mirus O, Bredemeier R, Hempel F, Maier UG, Schleiff E (2010) Filling the gap, evolutionarily conserved Omp85 in plastids of chromalveolates. J Biol Chem 285:6848-6856

Burkhardt S, Amoroso G, Riebesell U, Sültemeyer D (2001) $\mathrm{CO}_{2}$ and $\mathrm{HCO}_{3}{ }^{-}$uptake in marine diatoms acclimated to different $\mathrm{CO}_{2}$ concentrations. Limnol Oceanogr 46:1378-1391

Cavalier-Smith T (1999) Principles of protein and lipid targeting in secondary symbiogenesis: euglenoid, dinoflagellate, and sporozoan plastid origins and the eukaryote family tree. J Eukaryot Microbiol 46:347-366

Cavalier-Smith T (2000) Membrane heredity and early chloroplast evolution. Trends Plant Sci 5:174-182

Chaal BK, Ishida K, Green BR (2003) A thylakoidal processing peptidase from the heterokont alga Heterosigma akashiwo. Plant Mol Biol 52:463-472

Chan CX, Reyes-Prieto A, Bhattacharya D (2011) Red and green algal origin of diatom membrane transporter: insights into environmental adaptation and cell evolution. PLoS One 6:e29138

Chan CX, Bhattacharya D, Reyes-Prieto A (2012) Endosymbiotic and horizontal gene transfer in microbial eukaryotes: impacts on cell evolution and the tree of life. Mob Genet Elem 2:101-105

Chen Y, Cann MJ, Litvin TN, Iourgenko V, Sinclair ML, Levin LR, Buck J (2000) Soluble adenylyl cyclase as an evolutionarily conserved bicarbonate sensor. Science 289:625-628

Collin V, Issakidis-Bourguet E, Marchand C, Hirasawa M, Lancelin JM, Knaff DB, Miginiac-Maslow M (2003) The Arabidop plastidial thioredoxins: new functions and new insights into specificity. J Biol Chem 278:23747-23752

Colman B, Rotatore C (1995) Photosynthetic inorganic carbon uptake and accumulation in two marine diatoms. Plant Cell Environ 18:919-924

Cox EH, McLendon GL, Morel FMM, Lane TW, Prince RC, Pickering IJ, George GN (2000) The active site structure of Thalassiosira weissflogii carbonic anhydrase 1. Biochemistry 39:12128-12130

Danson JS, Huertas IE, Colman B (2004) Source of inorganic carbon for photosynthesis in two marine dinoflagellates. J Phycol 40:285-292

De Riso V, Raniello R, Maumus F, Rogato A, Bowler C, Falciatore A (2009) Gene silencing in the marine diatom Phaeodactylum tricornutum. Nucl Acids Res 37:e96

Delwiche CF, Palmer JD (1997) The origin of plastids and their spread via secondary symbiosis. Plant Syst Evol 11:53-86

Deschamps P, Moreira D (2012) Reevaluating the green contribution to diatom genomes. Genome Biol Evol 4:683-688

Dionisio-Sese ML, Fukuzawa H, Miyachi S (1990) Light-induced carbonic anhydrase expression in Chlamydomonas reinhardtii. Plant Physiol 94:1103-1110

Dou Z, Heinhorst S, Williams EB, Murin CD, Shively JM, Cannon GC (2008) $\mathrm{CO}_{2}$ fixation kinetics of Halothiobacillus neapolitanus mutant carboxysomes lacking carbonic anhydrase suggest the shell acts as a diffusional barrier for $\mathrm{CO}_{2}$. J Biol Chem 283:10377-10384

Duanmu D, Spalding MH (2011) Insertional suppressors of Chlamydomonas reinhardtii that restore growth of air-dier lcib mutants in low $\mathrm{CO}_{2}$. Photosynth Res 109:123-132

Eisenhut M, Kahlon S, Hasse D, Ewald R, LiemanHurwitz J, Ogawa T, Ruth W, Bauwe H, Kaplan A, Hagemann M (2006) The plant-like C2 glycolate cycle and the bacterial like glycerate pathway cooperate in phophoglycolate metabolism in cyanobacteria. Plant Physiol 142:333-342

Fabris M, Matthijs M, Rombauts S, Vyverman W, Goossens A, Baart GJE (2012) The metabolic blueprint of Phaeodactylum tricornutum reveals a eukaryotic Entner-Doudoroff glycolytic pathway. Plant J 70:1004-1014

Falkowski PG, Raven JA (2007) Aquatic photosynthesis, 2nd edn. Princeton University Press, Princeton

Falkowski P, Scholes RJ, Boyle E, Canadell J, Canfield D, Elser J, Gruber N, Hibbard K, Hoegberg P, Linder S, Mackenzie FT, III Moore B, Pedersen T, Rosenthal Y, Seitzinger S, Smetacek V, Steffen W (2000) The global carbon cycle: a test of our knowledge of Earth as a system. Science 290:291-296

Fukuzawa H, Suzuki E, Komukai Y, Miyachi S (1992) A gene homologous to chloroplast carbonic anhydrase (icfA) is essential to photosynthetic carbon dioxide fixation by Synechococcus PCC7942. Proc Natl Acad Sci U S A 89:4437-4441

Fukuzawa H, Miura K, Ishizaki K, Kucho KI, Saito T, Kohinata T, Ohyama K (2001) Ccm 1, a regulatory gene controlling the induction of a carbonconcentrating mechanism in Chlamydomonas reinhardtii by sensing $\mathrm{CO}_{2}$ availability. Proc Natl Acad Sci U S A 98:5347-5352

Funke RP, Kovar JL, Weeks DP (1997) Intracellular carbonic anhydrase is essential to photosynthesis in Chlamydomonas reinhardtii at atmospheric levels of 
$\mathrm{CO}_{2}$. Demonstration via genomic complementation of the high- $\mathrm{CO}_{2}$-requiring mutant ca-1. Plant Physiol 114:237-244

Genkov T, Meyer M, Griffiths H, Spreitzer RJ (2010) Functional hybrid RubisCO enzymes with plant small subunits and algal large subunits: engineered rbcS cDNA for expression in Chlamydomonas. J Biol Chem 285:19833-19841

Giordano M, Norici A, Forssen M, Eriksson M, Raven JA (2003) An anaplerotic role for mitochondrial carbonic anhydrase in Chlamydomonas reinhardtii. Plant Physiol 132:2126-2134

Goyet C, Poisson A (1989) New determination of carbonic acid dissociation constants in seawater as a function of temperature and salinity. Deep-Sea Res 36:1635-1654

Gruber A, Vugrinec S, Hempel F, Gould SB, Maier UG, Kroth PG (2007) Protein targeting into complex diatom plastids depends on the signal peptide's cleavage site within the bipartite presequence. Plant Mol Biol 64:519-530

Gruber A, Weber T, Bártulos CR, Vugrinec S, Kroth PG (2009) Intracellular distribution of the reductive and oxidative pentase phosphate pathways in two diatoms. J Basic Microbiol 49:58-72

Haimovich-Dayan M, Garfinkel N, Ewe D, Marcus Y, Gruber A, Wagner H, Kroth PG, Kaplan A (2013) The role of $\mathrm{C}_{4}$ metabolism in the marine diatom Phaeodactylum tricornutum. New Phytol 197: 177-185

Hammer A, Hodgson DR, Cann MJ (2006) Regulation of prokaryotic adenylyl cyclases by $\mathrm{CO}_{2}$. Biochem J 396:215-218

Harada H, Matsuda Y (2005) Identification and characterization of a new carbonic anhydrase in the marine diatom Phaeodactylum tricornutum. Can J Bot 83:909-916

Harada H, Nakatsuma D, Ishida M, Matsuda Y (2005) Regulation of the expression of intracellular $\beta$-carbonic anhydrase in response to $\mathrm{CO}_{2}$ and light in the marine diatom Phaeodactylum tricornutum. Plant Physiol 139:1041-1050

Harada H, Nakajima K, Sakaue K, Matsuda Y (2006) $\mathrm{CO}_{2}$ sensing at ocean surface mediated by cAMP in a marine diatom. Plant Physiol 142:1318-1328

Holdsworth RH (1971) The isolation and partial characterization of the pyrenoid protein of Eremosphaera viridis. J Cell Biol 51:499-513

Hopkinson BM (2013) A chloroplast pump model for the $\mathrm{CO}_{2}$ concentrating mechanism in the diatom Phaeodactylum tricornutum. Photosynth Res. doi:10.1007/s11120-013-9954-7

Hopkinson BM, Dupont CL, Allen AE, Morel FMM (2011) Efficiency of the $\mathrm{CO}_{2}$-concentrating mecha- nism of diatoms. Proc Natl Acad Sci USA 108:3830-3837

Jenks A, Gibbs SP (2000) Immunolocalization and distribution of form II RubisCO in the pyrenoid and chloroplast stroma of Amphidinium carterae and form I RubisCO in the symbiont-derived plastids of Perinidium foliaceum (Dinophyceae). J Phycol 36:127-138

John-Mckay ME, Colman B (1997) Variation in the occurrence of external carbonic anhydrase among strains of the marine diatom Phaeodactylum tricornutum (Bacillariophyceae). J Phycol 33:988-990

Johnston AM, Raven JA (1996) Inorganic carbon accumulation by the marine diatom Phaeodactylum tricornutum. Eur J Phycol 31:285-290

Karlsson J, Clarke AK, Chen ZY, Hugghins SY, Park YI, Husic HD, Moroney JV, Samuelsson G (1998) A novel $\alpha$-type carbonic anhydrase associated with the thylakoid membrane in Chlamydomonas reinhardtii is required for growth at ambient $\mathrm{CO}_{2}$. EMBO J 17:1208-1216

Kerfeld CA, Sawaya MR, Tanaka S, Nguyen CV, Phillips M, Beeby M, Yeates TO (2005) Protein structures forming the shell of primitive bacterial organelles. Science 309:936-938

Kikutani S, Tanaka R, Yamazaki Y, Hara S, Hisabori T, Kroth PG, Matsuda Y (2012) Redox regulation of carbonic anhydrases via thioredoxin in the chloroplast of the marine diatom Phaeodactylum tricornutum. J Biol Chem 287:20689-20700

Kilian O, Kroth PG (2004) Presequence acquisition during secondary endocytobiosis and the possible role of introns. J Mol Evol 58:712-721

Kilian O, Kroth PG (2005) Identification and characterization of a new conserved motif within the presequence of proteins targeted into complex diatom plastids. Plant J 41:175-183

Kitao Y, Matsuda Y (2009) Formation of macromolecular complexes of carbonic anhydrases in the chloroplast of a marine diatom by the action of the C-terminal helix. Biochem J 419:681-688

Kitao Y, Harada H, Matsuda Y (2008) Localization and targeting mechanisms of two chloroplastic $\beta$-carbonic anhydrases in the marine diatom Phaeodactylum tricornutum. Physiol Plant 133:68-77

Klengel T, Liang WJ, Chaloupka J, Ruoff C, Schröppel K, Naglik JR, Eckert SE, Mogensen EG, Haynes K, Tuite MF, Levin LR, Buck J, Mühlschlegel FA (2005) Fungal adenylyl cyclase integrates $\mathrm{CO}_{2}$ sensing with cAMP signaling and virulence. Curr Biol 15:2021-2026

Kohinata T, Nishino H, Fukuzawa H (2008) Significance of zinc in a regulatory protein, CCM1, which regulates the carbon-concentrating mecha- 
nism in Chlamydomonas reinhardtii. Plant Cell Physiol 49:273-283

Kooistra WHCF, Gersonde R, Medlin LK, Mann DG (2007) The origin and evolution of the diatoms: their adaptation to a planktonic existence. In: Falkowski PG, Knoll AH (eds) Evolution of primary producers in the sea. Academic Press, Burlington, pp 207-249

Korb RE, Saville PJ, Johnston AM, Raven JA (1997) Sources of inorganic carbon for photosynthesis by three species of marine diatom. J Phycol 33:433-440

Kozaki A, Takeba G (1996) Photoinhibition protects $C_{3}$ plants from photooxidation. Nature 384:557-560

Kroth PG (2002) Protein transport into secondary plastids and the evolution of primary and secondary plastids. Int Rev Cytol 221:191-255

Kroth PG, Chiovitti A, Gruber A, Martin-Jezequel V, Mock T, Parker MS, Stanley MS, Kaplan A, Caron L, Weber T, Maheswari U, Armbrust EV, Bowler C (2008) A model for carbohydrate metabolism in the diatom Phaeodactylum tricornutum deduced from comparative whole genome analysis. PLoS One 3:e1426

Kuchitsu K, Tsuzuki M, Miyachi S (1988) Characterization of the pyrenoid isolated from unicellular green alga Chlamydomonas reinhardtii: particulate from RubisCO protein. Protoplasma 144:17-24

Kuchitsu K, Tsuzuki M, Miyachi S (1991) Polypeptide composition and enzyme activities of the pyrenoid and its regulation by $\mathrm{CO}_{2}$ concentration in unicellular green algae. Can J Bot 69:1062-1069

Kucho K, Ohyama K, Fukuzawa $\mathrm{H}$ (1999) $\mathrm{CO}_{2^{-}}$ responsive transcriptional regulation of $\mathrm{CAH} 1$ encoding carbonic anhydrase is mediated by enhancerand silencer regions in Chlamydomonas reinhardtii. Plant Physiol 121:1329-1337

Lacoste-Royal G, Gibbs SP (1987) Immunocytochemical localization of ribulose-1,5-bisphosphate carboxylase in the pyrenoid and thylakoid region of the chloroplast of Chlamydomonas reinhardtii. Plant Physiol 83:602-606

Lane TW, Morel FMM (2000) A biological function for cadmium in marine diatoms. Proc Natl Acad Sci U S A 97:4627-4631

Lane TW, Saito MA, George GN, Pickering IJ, Prince RC, Morel FMM (2005) A cadmium enzyme from marine diatom. Nature 435:42

Lang M, Kroth PG (2001) Diatom fucoxanthin chlorophyll $a / c$-binding protein (FCP) and land plant light-harvesting proteins use a similar pathway for thylakoid membrane insertion. J Biol Chem 276:7985-7991

Lang M, Apt KE, Kroth PG (1998) Protein transport into "complex" diatom plastids utilizes two different targeting signals. J Biol Chem 273:30973-30978
Lapointe M, Mackenzie TDB, Morse D (2008) An external $\delta$-carbonic anhydrase in a free-living marine dinoflagellate may circumvent diffusion-limited carbon acquisition. Plant Physiol 147:1427-1436

Lavaud J, Materna AC, Sturm S, Vugrinec S, Kroth PG (2012) Silencing of the violaxanthin de-epoxidase gene in the diatom Phaeodactylum tricornutum reduces diatoxanthin synthesis and non-photochemical quenching. PLoS One 7:e36806

Lee RBY, Smith JAC, Rickaby REM (2013) Cloning, expression and characterization of the $\delta$-carbonic anhydrase of Thalassiosira weissflogii (Bacillariophyceae). J Phycol 49:170-177

Lemaire SD, Miginiac-Maslow M (2004) The thioredoxin superfamily in Chlamydomonas reinhardtii. Photosynth Res 82:203-220

Lemaire SD, Collin V, Keryer E, Quesada A, MiginiacMasalow M (2003) Characterization of thioredoxin $\mathrm{y}$, a new type of thioredoxin identified in the genome of Chlamydomonas reinhardtii. FEBS Lett 543:87-92

Lemaire SD, Guillon B, Le Marechal P, Keryer E, Miginiac-Maslow M, Decottignies P (2004) New thioredoxin targets in the unicellular photosynthetic eukaryote Chlamydomonas reinhardtii. Proc Natl Acad Sci U S A 101:7475-7480

Liaud MF, Lichtlé C, Apt K, Martin W, Cerff R (2000) Compartment-specific isoforms of TPI and GAPDH are imported into diatom mitochondria as a fusion protein: evidence in favor of a mitochondrial origin of the eukaryotic glycolytic pathway. Mol Biol Evol $17: 213-223$

Long BM, Badger MR, Whitney SM, Price GD (2007) Analysis of carboxysomes from Synechococcus PCC7942 reveals multiuple RubisCO complexes with carboxysomal proteins $\mathrm{CcmM}$ and $\mathrm{CcaA}$. J Biol Chem 282:29323-29335

Lopez-Ruiz A, Verbelen JP, Roldan JM, Diez J (1985) Nitrate reductase of green algae is located in the pyrenoid. Plant Physiol 79:1006-1010

Maeda S, Badger MR, Price GD (2002) Novel gene products associated with NdhD3/D4-containing NDH-1 complexes are involved in photosynthetic $\mathrm{CO}_{2}$ hydration in the cyanobacterium Synechococcus sp. PCC7942. Mol Microbiol 43:425-436

Marcus Y, Harel E, Kaplan A (1983) Adaptation of the cyanobacterium Anabaena variabilis to low $\mathrm{CO}_{2}$ concentration in their environment. Plant Physiol $71: 208-210$

Matsuda Y, Colman B (1995a) Induction of $\mathrm{CO}_{2}$ and bicarbonate transport in green alga Chlorella ellipsoidea. Time course of induction of two systems. Plant Physiol 108:247-252

Matsuda Y, Colman B (1995b) Induction of $\mathrm{CO}_{2}$ and bicarbonate transport in green alga Chlorella ellip- 
soidea. Evidence for induction in response to external $\mathrm{CO}_{2}$ concentration. Plant Physiol 108:253-260

Matsuda Y, Hara T, Colman B (2001) Regulation of the induction of bicarbonate uptake by dissolved $\mathrm{CO}_{2}$ in the marine diatom Phaeodactylum tricornutum. Plant Cell Environ 24:611-620

Matsuda Y, Satoh K, Harada H, Satoh D, Hiraoka Y, Hara $T$ (2002) Regulation of the expressions of $\mathrm{HCO}_{3}{ }^{-}$uptake and intracellular carbonic anhydrase in response to $\mathrm{CO}_{2}$ concentrating in the marine diatom Phaeodactylum sp. Funct Plant Biol 29:279-287

Matsuda Y, Nakajima K, Tachibana M (2011) Recent progresses on the genetic basis of the regulation of $\mathrm{CO}_{2}$ acquisition systems in response to $\mathrm{CO}_{2}$ concentration. Photosynth Res 109:191-203

Matsuzaki M, Misumi O, Shin-I T, Maruyama S, Takahara M, Miyagishima S, Mori T, Nishida K, Yagisawa F, Nishida K, Yoshida Y, Nishimura Y, Nakao S, Kobayashi T, Momoyama Y, Higashiyama T, Minoda A, Sano M, Nomoto H, Oishi K, Hayashi H, Ohta F, Nishizaka S, Haga S, Miura S, Morishita T, Kabeya Y, Terasawa K, Suzuki Y, Ishii Y, Asakawa S, Takano H, Ohta N, Kuroiwa H, Tanaka K, Shimizu N, Sugano S, Sato N, Nozaki H, Ogasawara N, Kohara Y, Kuroiwa T (2004) Genome sequence of the ultrasmall unicellular red alga Cyanidioschyzon merolae 10D. Nature 428:653-657

Mayo WP, Williams TG, Birch DG, Turpin DH (1986) Photosynthetic adaptation by Synechococcus leopoliensis in response to exogenous dissolved inorganic carbon. Plant Physiol 80:1038-1040

McGinn PJ, Morel FMM (2008) Expression and inhibition of the carboxylating and decarboxylating enzymes in the photosynthetic $\mathrm{C}_{4}$ pathway of marine diatoms. Plant Physiol 146:300-309

McKay RML, Gibbs SP (1989) Immunocytochemical localization of ribulose-1,5-bisphosphate carboxylase/ oxygenase in light-limited and light-saturated cells of Chlorella pyrenoidosa. Protoplasma 149:31-37

McKay RML, Gibbs SP (1990) Phycoerythrin is absent from the pyrenoid of Porphyridium cruentum: photosynthetic implications. Planta 180:249-256

McKay RML, Gibbs SP, Vaughn KC (1991) RubisCO activase is present in the pyrenoid of green algae. Protoplasma 162:38-45

Mestres-Ortega D, Meyer Y (1999) The Arabidopsis thaliana genome encodes at least four thioredoxins $\mathrm{m}$ and a new prokaryotic-like thioredoxin. Gene 240:307-316

Meyer Y, Buchanan BB, Vignols F, Reichheld JP (2009) Thioredoxins and glutaredoxins: unifying elements in redox biology. Annu Rev Genet 43:335-367
Michels AK, Wedel N, Kroth PG (2005) Diatom plastids possess a phosphoribulokinase with an altered regulation and no oxidative pentose phosphate pathway. Plant Physiol 137:911-920

Milligan AJ, Morel FMM (2002) A proton buffering role for silica in diatoms. Science 297:1848-1850

Mitchell C, Beardall J (1996) Inorganic carbon uptake by an Antarctic sea-ice diatom, Nitzschia frigida. Polar Biol 16:95-99

Mitra M, Lato SM, Ynalvez RA, Xiao Y, Moroney JV (2004) Identification of a new chloroplast carbonic anhydrase in Chlamydomonas reinhardtii. Plant Physiol 135:173-182

Miura K, Kohinata T, Yoshioka S, Ohyama K, Fukuzawa H (2002) Regulation of a carbon concentrating mechanism through CCM1 in Chlamydomonas reinhardtii. Funct Plant Biol 29:211-219

Miura K, Yamano T, Yoshioka S, Kohinata T, Inoue Y, Taniguchi F, Asamizu E, Nakamura Y, Tabata S, Yamato KT, Ohyama K, Fukuzawa H (2004) Expression profiling-based identification of $\mathrm{CO}_{2}$-responsive genes regulated by CCM1 controlling a carbon-concentrating mechanism in Chlamydomonas reinhardtii. Plant Physiol 135: 1595-1607

Montsant A, Jabbari K, Maheswari U, Bowler C (2005) Comparative genomics of the pennate diatom Phaeodactylum tricornutum. Plant Physiol 137:500-513

Morita E, Abe T, Tsuzuki M, Fujiwara S, Sato N, Hirata A, Sonoike K, Nozaki H (1998) Presence of the $\mathrm{CO}_{2}$-concentraitng mechanism in some species of the pyrenoid-less free-living algal genus Chloromonas (Volvocales, Chlorophyta). Planta 204:269-276

Motohashi K, Kondoh A, Stumpp MT, Hisabori T (2001) Comprehensive survey of proteins targeted by chloroplast thioredoxin. Proc Natl Acad Sci U S A 98:11224-11229

Moustafa A, Reyes-Prieto A, Bhattacharya D (2008) Chlamydiae has contributed at least 55 genes to Plantae with predominantly plastids functions. PLoS One 3:e2205

Moustafa A, Beszteri B, Maier UG, Bowler C, Valentin K, Bhattacharya D (2009) Genomic footprints of a cryptic plastid endosymbiosis in diatoms. Science 324:1724-1726

Mueller-Cajar O, Stotz M, Wendler P, Hartl FU, Bracher A, Hayer-Hartl M (2011) Structure and function of the $\mathrm{AAA}^{+}$protein $\mathrm{CbbX}$, a red-type RubisCO activase. Nature 479:194-199

Nakajima K, Tanaka A, Matsuda Y (2013) SLC4 family transporters in a marine diatom directly pump bicarbonate from seawater. Proc Natl Acad Sci USA 110(5):1767-1772 
Nimer NA, Brownlee C, Merrett MJ (1999) Extracellular carbonic anhydrase facilitates carbon dioxide availability for photosynthesis in the marine dinoflagellate Prorocentrum micans. Plant Physiol 120:105-112

Nishimura T, Takahashi Y, Yamaguchi O, Suzuki H, Maeda S, Omata T (2008) Mechanism of low $\mathrm{CO}_{2-}$ induced activation of the $\mathrm{cmp}$ bicarbonate transporter operon by a LysR family protein in the cyanobacterium Synechococcus elongatus strain PCC 7942. Mol Microbiol 68:98-109

Norton TA, Melkonian M, Anderson RA (1996) Algal biodiversity. Phycologia 35:308-326

Ohnishi N, Mukherjee B, Tsujikawa T, Yanase M, Nakano H, Moroney JV, Fukuzawa H (2010) Expression of a low $\mathrm{CO}_{2}$-inducible protein, LCI1, increases inorganic carbon uptake in the green alga Chlamydomonas reinhardtii. Plant Cell 22:3105-3117

Ohno N, Inoue T, Yamashiki R, Nakajima K, Kitahara Y, Ishibashi M, Matsuda Y (2012) $\mathrm{CO}_{2}$-cAMPresponsive cis-elements targeted by a transcription factor with CREB/ATF-like basic zipper domain in the marine diatom Phaeodactylum tricornutum. Plant Physiol 158:499-513

Omata T, Price GD, Badger MR, Okamura M, Gohta S, Ogawa T (1999) Identification of an ATP-binding cassette transporter involved in bicarbonate uptake in the cyanobacterium Synechococcus sp. strain PCC 7942. Proc Natl Acad Sci U S A 96:13571-13576

Omata T, Gohta S, Takahashi Y, Harano Y, Maeda S (2001) Involvement of a CbbR homolog in low $\mathrm{CO}_{2}$ induced activation of the bicarbonate transporter operon in cyanobacteria. J Bacteriol 183:1891-1898

Osafune T, Yokota A, Sumida S, Hase E (1990) Immunogold localization of ribulose-1, 5-bisphosphate carboxylase with reference to pyrenoid morphology in chloroplasts of synchronized Euglena gracilis cells. Plant Physiol 92:802-808

Oudot-Le Secq MP, Green BR (2011) Complex repeat structures and novel features in the mitochondrial genomes of the diatoms Phaeodactylum tricornutum and Thalassiosira pseudonana. Gene 476:20-26

Oudot-Le Secq MP, Grimwood J, Shapiro H, Armbrust EV, Bowler C, Green BV (2007) Chloroplast genomes of the diatoms Phaeodactylum tricornutum and Thalassiosira pseudonana: comparison with other plastid genomes of the red lineage. Mol Genet Genomics 277:427-439

Parker MS, Armbrust EV, Piovia-Scott J, Keil RG (2004) Induction of photorespiration by light in the centric diatom Thalassiosira weissflogii (Bacillariophyceae): molecular characterization and physiological consequences. J Phycol 40:557-567
Patel BN, Merrett MJ (1986) Inorganic-carbon uptake by the marine diatom Phaeodactylum tricornutum. Planta 169:222-227

Paul JS, Volcani BE (1974) Photorespiration in diatoms I. The oxidation of glycolic acid in Thalassiosira pseudonana. Arch Microbiol 101:115-120

Paul JS, Volcani BE (1976) Photorespiration in diatoms IV. Two pathways of glycolate metabolism in synchronized cultures of Cylindrotheca fuciformis. Arch Microbiol 110:247-252

Poulsen N, Chesley PM, Kröger N (2006) Molecular genetic manipulation of the diatom Thalassiosira pseudonana (Bacillariophyceae). J Phycol 42:1059-1065

Price GD, Woodger FJ, Badger MR, Howitt SM, Tucker L (2004) Identification of a SulP-type bicarbonate transporter in marine cyanobacteria. Proc Natl Acad Sci U S A 101:18228-18233

Prihoda J, Tanaka A, de Paula WBM, Allen JF, Tirichine L, Bowler C (2012) Chloroplastmitochondria cross-talk in diatoms. J Exp Bot 63:1543-1557

Pronina NA, Semenenko VE (1984) Localization of membrane bound and soluble forms of carbonic anhydrase in the Chlorella cell. Fiziol Rast (Moscow) 31:241-251

Qiu H, Yoon HS, Bhattacharya D (2013) Algal endosymbionts as vectors of horizontal gene transfer in photosynthetic eukaryotes. Front Plant Sci 19:366

Ratti S, Giordano M, Morse D (2007) $\mathrm{CO}_{2}$-concentrating mechanisms of the potentially toxic dinoflagellate Protoceratium reticulatum (Dinophyceae, Gonyaulacales). J Phycol 43:693-701

Raven JA (1997) $\mathrm{CO}_{2}$-concentrating mechanisms: a direct role for thylakoid lumen acidification? Plant Cell Environ 20:147-154

Reinfelder JR, Kraepiel AML, Morel FMM (2000) Unicellular $\mathrm{C}_{4}$ photosynthesis in a marine diatom. Nature 407:996-999

Reinfelder JR, Milligan AJ, Morel FMM (2004) The Role of the $\mathrm{C}_{4}$ pathway in carbon accumulation and fixation in a marine diatom. Plant Physiol 135:2106-2111

Roberts SB, Lane TW, Morel FMM (1997) Carbonic anhydrase in the marine diatom Thalassiosira weissflogii (Bacillariophyceae). J Phycol 33:845-850

Roberts K, Granum E, Leegood RC, Raven JA (2007a) Carbon acquisition by diatoms. Photosynth Res 93:79-88

Roberts K, Granum E, Leegood RC, Raven JA (2007b) $C_{3}$ and $C_{4}$ pathways of photosynthetic carbon assimilation in marine diatoms are under genetic, not environmental, control. Plant Physiol 145:230-235 
Rogers M, Keeling PJ (2004) Lateral transfer and recompartmentalization of Calvin cycle enzymes of plants and algae. J Mol Evol 58:367-375

Rost B, Riebesell U, Burkhardt S (2003) Carbon acquisition of bloom-forming marine phytoplankton. Limnol Oceanogr 48:55-67

Rotatore C, Colman B, Kuzuma M (1995) The active uptake of carbon dioxide by the marine diatom Phaeodactylum triconrutum and Cyclotella sp. Plant Cell Environ 18:913-918

Sakaguchi T, Nakajima K, Matsuda Y (2011) Identification of the UMP stnthase gene by establishment of uracil auxotrophic mutants and the phenotypic complementation system in the marine diatom Phaeodactylum tricornutum. Plant Physiol 156:78-89

Samukawa M, Shen C, Hopkinson BM, Matsuda Y (2014) Localization of putative carbonic anhydrases in the marine diatom, Thalassiosira pseudonana. Photosynth Res. doi:10.1007/s11120-014-9967-x

Satoh D, HiraokaY, Colman B, Matsuda Y (2001) Physiological and molecular biological characterization of intracellular carbonic anhydrase from the marine diatom Phaeodactylum tricornutum. Plant Physiol 126:1459-1470

Sawaya MR, Cannon GC, Heinhorst S, Tanaka S, Williams EB, Yeates TO, Kerfeld CA (2006) The structure of $\beta$-carbonic anhydrase from the carboxysomal shell reveals a distinct subclass with one active site for the price of two. J Biol Chem 281:7546-7455

Schuerman P, Jacquot JP (2000) Plant thioredoxin systems revisited. Annu Rev Plant Physiol Plant Mol Biol 51:371-400

Shibata M, Katoh H, Sonoda M, Ohkawa H, Shimoyama M, Fukuzawa H, Kaplan A, Ogawa T (2002) Genes essential to sodium-dependent bicarbonate transport in cyanobacteria: function and phylogenetic analysis. J Biol Chem 277:18658-18664

Sims PA, Mann DG, Medlin LK (2006) Evolution of the diatoms: insights from fossil, biological and molecular data. Phycologia 45:361-402

So AK, Cot SSW, Espie GS (2002) Characterization of the C-terminal extension of carboxysomal carbonic anhydrase from Synechocystis sp PCC6803. Funct Plant Biol 29:183-194

So AK, Espie GS, Williams EB, Shively JM, Heinhorst S, Cannon GC (2004) A novel evolutionary lineage of carbonic anhydrase ( $\varepsilon$ class) is a component of the carboxysome shell. J Bacteriol 186:623-630

Sommer MS, Gould SB, Lehmann P, Gruber A, Przyborski JM, Maier UG (2007) Der1-mediated preprotein import into the periplastid compartoment of chromalveolates? Mol Biol Evol 24:918-928
Soto AR, Zheng H, Shoemaker D, Rodriguez J, Read BA, Wahlund TM (2006) Identification and preliminary characterization of two cDNAs encoding unique carbonic anhydrases from the marine alga Emiliania huxleyi. Appl Environ Microbiol 72:5500-5511

Spalding MH, Spreitzer RJ, Ogren WL (1983) Carbonic anhydrase-deficient mutant of Chlamydomonas reinhardtii requires elevated carbondioxide concentration for photoautotrophic growth. Plant Physiol 73:268-272

Sueltemeyer DF, Fock HP, Canvin DT (1991) Active uptake of inorganic carbon by Chlamydomonas reinhardtii: evidence for simultaneous transport of $\mathrm{HCO}_{3}{ }^{-}$and $\mathrm{CO}_{2}$ and characterization of active $\mathrm{CO}_{2}$ transport. Can J Bot 69:995-1002

Suzuki K, Iwamoto K, Yokoyama S, Ikawa T (1991) Glycolate-oxidizing enzymes in algae. J Phycol 27:492-498

Tachibana M, Allen AE, Kikutani S, Endo Y, Bowler C, Matsuda Y (2011) Localization of putative carbonic anhydrases in two marine diatoms, Phaeodactylum tricornutum and Thalassiosira pseudonana. Photosynth Res 109:205-221

Tanaka Y, Nakatsuma D, Harada H, Ishida M, Matsuda Y (2005) Localization of soluble $\beta$-carbonic anhydrase in the marine diatom Phaeodactylum tricornutum. Sorting to the chloroplast and cluster formation on the girdle lamellae. Plant Physiol 138:207-217

Tanaka R, Kikutani S, Mahardika A, Matsuda Y (2014) Localization of enzymes relating to $\mathrm{C}_{4}$ organic acid metabolisms in the marine diatom, Thalassiosira pseudonana. Photosynth Res. doi:10.1007/s11120014-9968-9

Tchernov D, Hassidim M, Luz B, Sukenik A, Reinhold L, Kaplan A (1997) Sustained net $\mathrm{CO}_{2}$ evolution during photosynthesis by marine microorganism. Curr Biol 7:723-728

Teich R, Zauner S, Baurain D, Brinkmann H, Petersen $\mathrm{J}$ (2007) Origin and distribution of Calvin cycle fructose and sedoheptulase bisphosphatases in plantae and complex algae: a single secondary origin of complex red plastids and subsequent propagation via tertiary endosymbioses. Protist 158:263-276

Tréguer P, Nelson DM, Bennekom AJ, DeMaster DJ, Leynaert A, Quéquiner B (1995) The silica balance in the world ocean: a reestimate. Science 268: 375-379

Trimborn S, Lundholm N, Thomas S, Richter KU, Krock B, Hansen PJ, Rost B (2008) Inorganic carbon acquisition in potentially toxic and non-toxic diatoms: the effect of $\mathrm{pH}$-induced changes in seawater carbonate chemistry. Physiol Plant 133:92-105 
Tripp BC, Smith K, Ferry JG (2001) Carbonic anhydrase: new insights for an ancient enzyme. J Biol Chem 276:48615-48618

Uehlein N, Lovisolo C, Siefritz F, Kaldenhoff R (2003) The tobacco aquaporin NtAQP1 is a membrane $\mathrm{CO}_{2}$ pore with physiological functions. Nature 425:734-737

Van K, Spalding MH (1999) Periplasmic carbonic anhydrase structural gene (Cah1) mutant in Chlamydomonas reinhardtii. Plant Physiol 120:757-764

Vaughn KC, Campbell EO, Hasegawa J, Owen HA, Renzaglia KS (1990) The pyrenoid is the site of ribulose 1,5-bisphosphate carboxylase/oxygenase accumulation in the hornwort (Bryophyta: Anthocerotae) chloroplast. Protoplasma 156:117-129

Viparelli F, Monti SM, De Simone G, Innocenti A, Scozzafava A, Xu Y, Morel FMM, Supuran CT (2010) Inhibition of the R1 fragment of the cadmium-containing $\zeta$-class carbonic anhydrase from the diatom Thalassiosira weissflogii with anions. Bioorg Med Chem Lett 20:4745-4748

Wang Y, Spalding MH (2006) An inorganic carbon transport system responsible for acclimation specific to air levels of $\mathrm{CO}_{2}$ in Chlamydomonas reinhardtii. Proc Natl Acad Sci U S A 103:10110-10115

Wang Y, Sun ZH, Horken KM, Im CS, Xiang Y, Grossman AR, Weeks DP (2005) Analyses of CIA5, the master regulator of the carbon-concentrating mechanism in Chlamydomonas reinhardtii, and its control of gene expression. Can J Bot 83:765-779

Weber T, Gruber A, Kroth PG (2009) The presence and localization of thioredoxins in diatoms, unicellular algae of secondary endosymbiotic origin. Mol Plant 2:468-477

Wilhelm C, Büchel C, Fisahn J, Goss R, Jakob T, Laroch J, Lavaud J, Lohr M, Riebesell U, Stehfest K, Valentin K, Kroth PG (2006) The regulation of carbon and nutrient assimilation in diatoms is significantly different from green algae. Protist 157:91-124

Wittpoth C, Kroth PG, Weyrauch K, Kowallik KV, Strotmann H (1998) Functional characterization of isolated plastids from two marine diatoms. Planta 206:79-85

Xiang YB, Zhang J, Weeks DP (2001) The Cia5 gene controls formation of the carbon concentrating mechanism in Chlamydomonas reinhardtii. Proc Natl Acad Sci U S A 98:5341-5346

Xu Y, Feng L, Jeffrey PD, Morel FMM (2008) Structure and metal exchange in the cadmium carbonic anhydrase of marine diatoms. Nature 452:56-61

Yamano T, Miura K, Fukuzawa H (2008) Expression analysis of genes associated with the induction of the carbon-concentrating mechanism in Chlamydomonas reinhardtii. Plant Physiol 147:340-354

Yamano T, Tsujikawa T, Hatano K, Ozawa SI, Takahashi Y, Fukuzawa H (2010) Light and low$\mathrm{CO}_{2}$ dependent LCIB-LCIC complex localization in the chloroplast supports the carbon-concentrating mechanism in Chlamydomonas reinhardtii. Plant Cell Physiol 51:1453-1468

Ynalvez RA, Xiano Y, Ward AS, Cunnusamy K, Moroney JV (2008) Identification and characterization of two closely related $\beta$-carbonic anhydrases from Chlamydomonas reinhardtii. Physiol Plant 133: 15-26

Yoon HS, Hackett JD, Pinto G, Bhattacharya D (2002) The single, ancient origin of chromist plastids. Proc Natl Acad Sci U S A 99:15507-15512

Zaslavskaia LA, Lippmeier JC, Kroth PG, Grossman AR, Apt KE (2000) Transformation of the diatom Phaeodactylum tricornutum (Bacillariophyceae) with a variety of selectable marker and reporter genes. J Phycol 36:379-386 